\title{
əInfluences of Atmospheric Rivers on North Pacific Winter Precipitation: Climatology and Dependence on ENSO Condition
}

\author{
YAting Xiong ${ }^{\mathrm{a}}$ AND Xuejuan Ren ${ }^{\mathrm{a}}$ \\ ${ }^{\text {a } C M A-N J U ~ J o i n t ~ L a b o r a t o r y ~ f o r ~ C l i m a t e ~ P r e d i c t i o n ~ S t u d i e s, ~ I n s t i t u t e ~ f o r ~ C l i m a t e ~ a n d ~ G l o b a l ~ C h a n g e ~ R e s e a r c h, ~}$ \\ School of Atmospheric Sciences, Nanjing University, Nanjing, China
}

(Manuscript received 26 April 2020, in final form 2 October 2020)

\begin{abstract}
The atmospheric river (AR) is a unique mover of moisture from the low latitudes to mid- and high latitudes and a potential cause for regional flooding. This study explores the ARs' influence on wintertime precipitation (including extreme precipitation) over the pan-North Pacific during 1996-2018 from the climatological perspective and during the ENSO condition, via distinguishing precipitation and moisture transport between the AR-group and the non-AR-group. Climatologically, the AR-group contributes $30 \%-45 \%$ of total winter precipitation, and up to $70 \%$ of total extreme precipitation over the eastern Pacific and along the North American west coast between $25^{\circ}$ and $45^{\circ} \mathrm{N}$. The above area is the core region of the ARs' influence on precipitation. The AR-group's precipitation in the core region is mostly determined by AR-produced in situ moisture convergence, while the non-AR-group's precipitation is attributed to evaporation from Earth's surface. The AR frequency is increased (decreased) in the core region during El Niño (La Niña) winters. As a result, the AR-group contributes more than half of the positive (negative) anomalies in total precipitation in the core region, due to AR-related moisture convergence anomalies. Besides, during El Niño winters, the AR-group also contributes almost half of negative anomalies in total precipitation over the middle basin between $40^{\circ}$ and $55^{\circ} \mathrm{N}$. An anomalous moisture sink (source) always acts to increase (decrease) in situ precipitation for both the AR-group and the non-AR-group. It is also shown that the moisture transport and its divergence anomalies are primarily decided by changes in wind fields and second by moisture. Furthermore, changes in moisture can cause asymmetric features of anomalies in moisture transport and its divergence between El Niño and La Niña but with limited effects.
\end{abstract}

KEYWORDS: Atmospheric circulation; ENSO; Extreme events; Precipitation; Water vapor; Interannual variability

\section{Introduction}

Atmospheric moisture transport and its convergence are primary processes to form precipitation (Trenberth 1999; Sohn et al. 2004; Trenberth et al. 2007; Chen et al. 2004; Schneider et al. 2010). The feature of moisture transport shows diversity over the ocean basins (e.g., the North Pacific and the North Atlantic). The time-mean circulation moves moisture zonally within ocean basins (Trenberth 1999; Newman et al. 2012). The filament-shaped conduits with large water vapor transport, often called atmospheric rivers (ARs), transport moisture from the lower latitudes to the middle and high latitudes (Newell et al. 1992; Zhu and Newell 1998; Ralph et al. 2006; Dettinger 2013; Guan and Waliser 2015; Liu et al. 2016; Guan et al. 2018; Nash et al. 2018; Ralph et al. 2019). Due to copious moisture fluxes, ARs have a crucial role in shaping the precipitation over the pan-North Pacific region (Kim et al. 2013; Kamae et al. 2017; Tsuji and Takayabu 2019). After traveling northeastward through ocean region, some ARs make landfall and create flooding, extreme precipitation events and other impacts over the west coast regions (Neiman et al. 2008; Guan et al. 2010; Lavers and Villarini 2015; Payne and Magnusdottir 2014; Gimeno et al. 2016; Hagos et al. 2016; Waliser and Guan 2017;

๑ Denotes content that is immediately available upon publication as open access.

Corresponding author: Xuejuan Ren, renxuej@nju.edu.cn
Brands et al. 2017; Ralph et al. 2019). Because of above hydrological influences and their unique meteorological characteristics, ARs have become an important issue in the field of hydrometeorology over the past decade (Ralph et al. 2017, 2019; Shields et al. 2018; DeFlorio et al. 2018).

ARs in the North Pacific occur mostly over the central basin between $20^{\circ}$ and $40^{\circ} \mathrm{N}$ and curve to the northeastern Pacific during winter (Rutz et al. 2014; Guan and Waliser 2015; Mundhenk et al. 2016; Kamae et al. 2017). Landfalling ARs and their influences on land were well documented. Landfalling ARs often create large amounts of precipitation over the western United States (Neiman et al. 2008; Lavers and Villarini 2015; Eldardiry et al. 2019). They contribute $30 \%-50 \%$ of all precipitation along the U.S. West Coast (Dettinger et al. 2011; Dettinger 2013), and $10 \%-30 \%$ of the cold-season precipitation totals in California (Kim et al. 2013). It has been reported that the majority of extreme precipitation along the West Coast is associated with ARs (Warner et al. 2012; Gimeno et al. 2016). The extreme precipitation events (EPEs) are largely fueled by abundant water vapor transported by landfalling ARs from the Pacific to the mountainous region (Leung and Qian 2009; Rivera et al. 2014; Waliser and Guan 2017; Lu et al. 2018).

Compared to landfalling ARs, ARs over the ocean region carry plenty of moisture equally. Some of the transported moisture converges over the ocean region, being favorable to in situ precipitation. However, the contribution of ARs to the precipitation over the North Pacific is unclear. In addition, climatic extremes like extreme precipitation, heat waves and wind extremes also occur over the ocean regions (Malloy et al. 
2015; Waliser and Guan 2017; Oliver et al. 2018). Those extreme events have nonnegligible impacts on the ocean ecosystem and marine transportation. Thus, investigation about the ARs' impact on the precipitation, including extreme precipitation over the whole pan-North Pacific is required.

El Niño-Southern Oscillation (ENSO) affects the interannual variability of precipitation and extreme precipitation over the pan-North Pacific region. During El Niño winters, greater precipitation over the southernmost United States and drier conditions over the midlatitude United States are observed (Ropelewski and Halpert 1986; Brown and Comrie 2004; Larkin and Harrison 2005; Yu and Zou 2013; Deser et al. 2018). Meanwhile, increased precipitation is seen over southeastern China (Dai and Wigley 2000; Chou et al. 2009; Feng et al. 2010; Zhou et al. 2014). The southwest United States responds to El Niño with strong increases in extreme precipitation, while Southeast Asia experiences moderate increases in extreme precipitation (Cayan et al. 1999; Meehl et al. 2007; Kenyon and Hegerl 2010).

ENSO influences the precipitation via altering the moisture transport (Ropelewski and Halpert 1987; Wang et al. 2000; Seager et al. 2012; Kim and Alexander 2015; Yang et al. 2018). During El Niño winters, positive anomalies in moisture transport extend equatorward over the middle Pacific basin, and then move northeastward toward the west coast of North America as a result of a deeper Aleutian low. Over the western Pacific, anomalous northeastward transport of moisture along eastern costal China is observed (Chen et al. 2014; Wang and Chen 2010; Zhou and $\mathrm{Wu}$ 2010). ENSO also affects the interannual variability of ARs frequency over the North Pacific (Payne and Magnusdottir 2014; Guan and Waliser 2015; Kim and Alexander 2015; Kim et al. 2017). However, as a distinctive form of moisture transports, the role of ARs in precipitation anomalies during ENSO winters over the North Pacific is unclear. In this study, we divided daily precipitation over the North Pacific into two groups: during AR days and non-AR days. Based on this thought, we can underscore the ARs' influence on precipitation, including extreme precipitation over the pan-North Pacific on climatological aspect and during ENSO winters.

The goal of the study is to unveil AR's influence on precipitation, including extreme precipitation, over the pan-North Pacific on climatology and dependence on ENSO condition. The paper is organized as follows: section 2 describes the data and methods. Section 3 shows the climatological features of ARs, moisture transport and precipitation over the pan-North Pacific, and AR's contribution. Section 4 analyzes the anomalies in ARs during ENSO winters, and the role of ARs in precipitation anomalies. Section 5 discusses the relative contributions of dynamic, thermodynamic and nonlinear processes to the anomalies in moisture transport. Section 6 focuses on extreme precipitation. Section 7 is conclusions and discussion.

\section{Data and methods}

\section{a. Data}

We use daily products from the European Centre for Medium-Range Weather Forecasts (ECMWF) interim reanalysis (ERA-Interim; Dee et al. 2011) for the period from 1
January 1979 to 28 February 2019 with resolution of $0.75^{\circ} \times$ $0.75^{\circ}$. The daily variables [specific humidity $q$, zonal $u$ and meridional $v$ winds at 1000, 925, 850, 700, 600, 500, 400, and $300 \mathrm{hPa}$, and surface latent heat flux] are averaged from twicedaily analysis, at 0000 and 1200 UTC. Evaporation is obtained by latent heat flux divided by the latent heat of vaporization $L_{e}$. Daily precipitation data are the satellite-gauge blend of the Global Precipitation Climatology Project (GPCP) One-Degree Daily Precipitation (version 1.2) from 1 October 1996 to 28 February 2019 with resolution of $1^{\circ} \times 1^{\circ}$, covering both ocean and land regions (Huffman et al. 2001). The Niño-3.4 index, defined as mean sea surface temperature (SST) anomalies in the equatorial central-eastern Pacific $\left(5^{\circ} \mathrm{S}-5^{\circ} \mathrm{N}, 170^{\circ}-120^{\circ} \mathrm{W}\right)$, is used as an indicator of ENSO conditions (Trenberth 1997). Monthly values of the Niño-3.4 index are obtained from National Oceanic and Atmospheric Administration/Climate Prediction Center (NOAA/CPC). In this study, an El Niño (La Niña) event is selected when the Niño-3.4 index is above $1{ }^{\circ} \mathrm{C}$ (or below $-1^{\circ} \mathrm{C}$ ) for three consecutive months. There are nine El Niño events (1982/83, 1986/87, 1987/88, 1991/92, 1994/95, 1997/98, 2002/03, 2009/10, 2015/16), and seven La Niña events (1984/85, 1988/89, 1998/99, 1999/2000, 2007/08, 2010/11, 2011/ 12) meet above criteria from 1979 to 2018 . Among them, four El Niño (1997/98, 2002/03, 2009/10, 2015/16) and five La Niña events (1998/99, 1999/2000, 2007/08, 2010/11, 2011/12) are during 1996-2018. Because the GPCP data begins from 1996, the present study mainly focuses on the winter seasons (December, January, and February) from 1996 to 2018. When analyzing precipitation results, we also use the precipitation data in ERA-Interim from 1979 to 2018 in parallel.

\section{b. AR detection}

The integrated vapor transport (IVT) is calculated by using the following formula:

$$
\mathrm{IVT}=\frac{1}{g} \int_{p_{t}}^{p_{s}} q \mathbf{V} d p
$$

where $g$ represents the gravitational acceleration $\left(\mathrm{m} \mathrm{s}^{-2}\right), q$ is the specific humidity $\left(\mathrm{kg} \mathrm{kg}^{-1}\right), p_{s}$ is set to $1000 \mathrm{hPa}, p_{t}$ is set to $300 \mathrm{hPa}, p$ is the pressure (hPa), and $\mathbf{V}$ is the horizontal wind vector $\left(\mathrm{m} \mathrm{s}^{-1}\right)$. The ARs are detected using the technique developed by Guan and Waliser (2015). The process for AR detection isolates contiguous regions of enhanced IVT exceeding a certain threshold ( $>85$ th percentile or $100 \mathrm{~kg} \mathrm{~m}^{-1} \mathrm{~s}^{-1}$, whichever is greater) first. Then those regions are checked for the geometry requirements of length $>2000 \mathrm{~km}$, the ratio of length to width $>2$, the requirements on IVT direction and other considerations (see Guan and Waliser 2015). When a grid is in the detected AR region, it is declared as an AR grid, the corresponding date is grouped as an AR day. Otherwise, the grid is a non-AR grid and the corresponding date is a non-AR day. The AR frequency (the ratio of the number of AR days to the number of days in a whole winter) is calculated for winters during 1979-2018. The precipitation, IVT, and divergence of IVT $(\nabla \cdot$ IVT) in the AR days (AR-group) and non-AR days (non-AR-group) at each grid are summed up, respectively, to obtain their individual accumulated values for each winter. 


\section{c. Definition of 2-day extreme precipitation event}

Daily precipitation at each grid for each winter during 19962018 is ranked from small to large. Only days with daily precipitation exceeding $1 \mathrm{~mm}$ are counted, to ensure that dry days are excluded. The value at 95 th percentile is selected as the threshold for extreme precipitation (Peterson et al. 2008; Vittal et al. 2013; Hagos et al. 2016; Lu et al. 2018). The procedure for identifying a 2-day extreme precipitation event (2-day EPE) at a grid is as follows. 1) An extreme day with precipitation above the threshold of $95 \%$ is picked for a particular grid; 2 ) precipitation values in the day prior to the extreme day and after that are compared, and the day with larger value together with the extreme day are considered as a 2-day EPE. These two consecutive days are counted as EPE days (Wu et al. 2018; Shang et al. 2020). On this basis, an AREPE is defined when a 2-day EPE contains at least one AR day. Similarly, precipitation, IVT, and $\nabla$. IVT on the 2-day EPE days and AR-EPE days are also summed up, respectively.

\section{d. Decomposition of IVT and $\nabla \cdot I V T$}

The changes in moisture transport can be attributed to changes in the circulation (dynamic process), moisture (thermodynamic process), and nonlinear processes (Kim et al. 2017; Ren et al. 2017; G. Chen et al. 2019). When a variable is decomposed into its time mean (denoted with an overbar), interannual (denoted with a prime), and noninterannual components, IVT and $\nabla$. IVT on an interannual time scale [(IVT)' and $\left.(\nabla \cdot \text { IVT })^{\prime}\right]$ can be expressed, respectively, as

$$
\begin{aligned}
\underbrace{\frac{1}{g} \int_{p_{t}}^{p_{s}}(q \mathbf{V})^{\prime} d p}_{\mathrm{T}}= & \underbrace{\frac{1}{g} \int_{p_{t}}^{p_{s}}\left(\bar{q} \mathbf{V}^{\prime}\right) d p}_{\mathrm{A}}+\underbrace{\frac{1}{g} \int_{p_{t}}^{p_{s}}\left(q^{\prime} \overline{\mathbf{V}}\right) d p}_{\mathrm{B}} \\
& +\underbrace{\frac{1}{g} \int_{p_{t}}^{p_{s}}\left(q^{\prime} \mathbf{V}^{\prime}\right) d p}_{\mathrm{C}}+\text { residual, } \\
\underbrace{\nabla \cdot \frac{1}{g} \int_{p_{t}}^{p_{s}}(q \mathbf{V})^{\prime} d p}_{\mathrm{T}}= & \underbrace{\nabla \cdot \frac{1}{g} \int_{p_{t}}^{p_{s}}\left(\bar{q} \mathbf{V}^{\prime}\right) d p}_{\mathrm{A}}+\underbrace{\nabla \cdot \frac{1}{g} \int_{p_{t}}^{p_{s}}\left(q^{\prime} \overline{\mathbf{V}}\right) d p}_{\mathrm{B}} \\
& +\underbrace{\nabla \cdot \frac{1}{g} \int_{p_{t}}^{p_{s}}\left(q^{\prime} \mathbf{V}^{\prime}\right) d p}_{\mathrm{C}}+\text { residual. }
\end{aligned}
$$

Equations (2) and (3) indicate that interannual variability of IVT and $\nabla$. IVT (term $\mathrm{T}$ ) can be decomposed into dynamic process (term A), thermodynamic process (term B), nonlinear process of interannual variables (term $\mathrm{C}$ ) and residual term. The residual term represents other nonlinear interaction besides term $\mathrm{C}$ (e.g., between interannual and noninterannual components). The residual term is much smaller and ignorable in this study (not shown).

The procedure of extracting the components of interannual variations from daily data has two steps. First, the daily climatology is removed from the daily data. Second, the daily anomalies are filtered using the Butterworth filter (Murakami 1979). The filtering window is from 90 days to 8 years.

The $T$ test is used to examine the credibility of the differences between two sample groups (Chervin and Schneider 1976; Zwiers and Storch 1995; Q. Chen et al. 2019). There are $l$ winters including $m$ El Niño winters and $n$ La Niña winters. We take the test on $m$ El Niño winters for example. The $\overline{x^{l}}$ and $\overline{x^{m}}$ in (4) and (5) are the mean values of the variable $X$ of these two sample groups. With the null hypothesis that the overall averages of the two samples have no significant differences, the statistics $t$ follows $t$ distribution with $(l+m-2)$ degrees of freedom. The $s^{2}$ in (5) is the unbiased estimator of the variance of the difference and $x_{i}$ is the winter accumulated value of each winter:

$$
\begin{aligned}
t & =\frac{\overline{x^{l}}-\overline{x^{m}}}{s \sqrt{\frac{1}{l}+\frac{1}{m}}} \\
s^{2} & =\frac{\sum_{i=1}^{l}\left(x_{i}^{l}-\overline{x^{l}}\right)^{2}+\sum_{i=1}^{m}\left(x_{i}^{m}-\overline{x^{m}}\right)^{2}}{l+m-2} .
\end{aligned}
$$

The corresponding critical value $t_{\alpha}$ can be found with a given significance level $(\alpha)$ and degrees of freedom. If $t>t_{\alpha}$, we reject the null hypothesis and think the differences are significant.

\section{Influence on winter precipitation: Climatological aspect}

Figure 1 depicts climatological winter accumulated precipitation and AR frequency over the pan-North Pacific. Winter accumulated GPCP precipitation is large in the midlatitude basin and along the North American west coast (Fig. 1a). The precipitation is more than $500 \mathrm{~mm}^{\text {winter }}{ }^{-1}$ over the central basin region, and more than $700 \mathrm{~mm}_{\text {winter }}{ }^{-1}$ along the northwest coastal region. ERA-Interim shows a similar pattern as GPCP over the pan-North Pacific region (Fig. 1b). However, it is higher than GPCP in the midlatitude basin. The main body of ARs with frequency of $11 \%$ or above occurs over the central Pacific and curves northeastward to the northwest coast (Fig. 1c). The ARs band with frequency of $7 \%$ or above also extends westward to southeast China. Above ARs features are consistent with previous studies (Guan and Waliser 2015; Mundhenk et al. 2016; Kamae et al. 2017).

Figure 2 plots climatological winter accumulated precipitation for AR-group and non-AR-group and AR fraction. The difference is robust between AR-group and non-AR-group over the whole ocean regions. Both GPCP and ERA-Interim show that precipitation for AR-group is concentrated in two regions: the midlatitude basin and northeastern Pacific, and along the North American northwest coast (Figs. 2a,d). Non-AR days' precipitation spreads over almost the whole North Pacific region, with large value along $40^{\circ} \mathrm{N}$ and along the northwest coast (Figs. 2b,e). The AR fraction of $30 \%-45 \%$ is conspicuous over the eastern Pacific and along the west coast between $25^{\circ}$ and $45^{\circ} \mathrm{N}$ (Fig. 2c) in which ARs frequency is about $5 \%-15 \%$ (Fig. 1c). Namely, ARs in the red box region are highly efficient in generation of precipitation. Thus, we pick the region over the eastern Pacific and along the west coast between $25^{\circ}$ and $45^{\circ} \mathrm{N}$ (red box region) as a core region of the ARs' influence on precipitation. The AR fraction in ERA-Interim is similar as that of GPCP, except that ERAInterim is slightly overestimated for $\mathrm{AR}$ fraction in the midlatitude basin and along the west coast between $20^{\circ}$ and $45^{\circ} \mathrm{N}$ (Fig. 2f).

ARs are well known as strong moisture conveyor belts. Therefore, it is necessary to show the differences of IVT and $\nabla$. IVT between AR-group and non-AR-group over the panNorth Pacific. Figure 3 plots climatological winter accumulated 
DJF precip GPCP

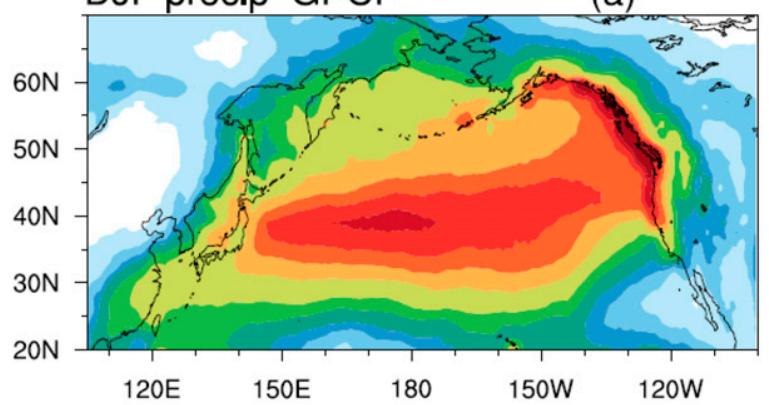

DJF precip ERA
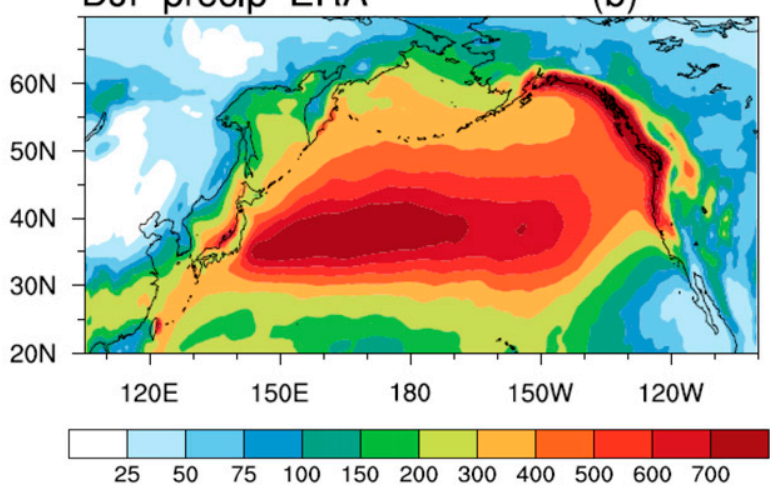

DJF AR frequency

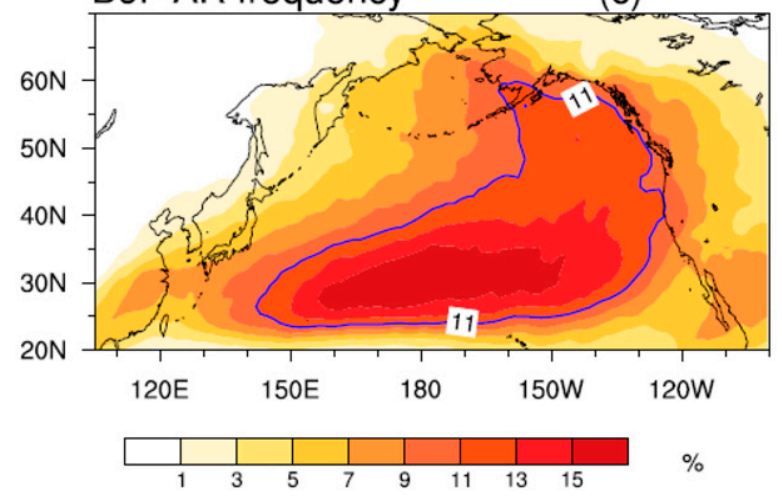

FIG. 1. Climatological winter accumulated precipitation (mm winter $^{-1}$ ) of (a) GPCP during 1996-2018 and (b) ERA-Interim during 1979-2018. (c) Climatological winter atmospheric rivers (AR) frequency (\%) during 1996-2018. The blue contour in (c) indicates climatological winter ARs frequency of $11 \%$ (the same below).

IVT and $\nabla \cdot$ IVT during 1996-2018 and those for AR-group and non-AR-group. Because of dominant westerly wind, climatological total IVT is mostly zonal over the extratropics to the west of the date line, and then poleward over the eastern margins of the North Pacific basin (Fig. 3a). It is no surprise to see that the IVT magnitude for AR-group is markedly stronger in the ARs main body region than it is around (Fig. 3b). The direction of IVT in the ARs main body region for AR-group is more poleward than that for non-AR-group (Figs. 3b,c).

Climatological winter total moisture sources are seen over the subtropics and the northwestern Pacific. Meanwhile, moisture sinks are observed over the northeastern Pacific-North American continent (Fig. 3a). There are considerable discrepancies between AR-group and non-AR-group over the pan-North Pacific. For AR-group, a moisture sink occupies almost the whole basin (Fig. 3b). For non-AR-group, a moisture sink is only seen over the northeastern Pacific north of $35^{\circ} \mathrm{N}$ (Fig. 3c). Both groups are important for the moisture sink over the North American west coast.

We now focus on the core region of the ARs' influence (the red box region in Fig. 2c, as well as Figs. 3b,c). According to the moisture budget (moisture balance equation) of an atmospheric column, precipitation $P$ is closely related with the processes of convergence of moisture transportation $\nabla$. IVT and evaporation at Earth's surface $E$ (Trenberth et al. 2007). In the core region, AR-group produces an in situ moisture sink $(\nabla \cdot$ IVT $<0$, Fig. 3b), while non-AR-group shows a moisture source $(\nabla \cdot$ IVT $>0)$ in general (Fig. 3c). Therefore, the closeness of relationship between $P$ and $\nabla$. IVT in the core region for AR-group is different from that for non-AR-group.

To demonstrate the above point, Fig. 4 depicts bar charts for climatological accumulated daily $P, \nabla \cdot$ IVT, and $E$ in the red box region during 1996-2018 winters, respectively, for all the AR grids and the non-AR grids. It is seen that, climatologically, AR-group's precipitation in the core region is mostly determined by the ARproduced moisture convergence $(\nabla \cdot$ IVT $<0)$ but not $E$, while, non-AR-group's precipitation is attributed to $E$, which is mainly caused by evaporative moisture flux from the ocean. For non-ARgroup, the divergence of moisture transport $(\nabla \cdot$ IVT $>0)$ in the core region is unfavorable to in situ precipitation.

\section{Influence on winter precipitation: Dependence on ENSO condition}

Figure 5a shows the composite of accumulated GPCP precipitation anomalies for the four El Niño winters during 1996-2018. During El Niño winters, an enhanced precipitation is seen over East Asia and its coastal waters, the eastern Pacific and the coastal areas of California. Meanwhile, a decreased one is located over the central basin. Figure 5d plots the composite anomalies in ARs frequency for the four El Niño winters during 1996-2018. ARs frequency is increased by about $3 \%-4 \%$ in the core region (the red box region). Meanwhile, ARs frequency is decreased over the regions of southwestern America and middle basin between $40^{\circ}$ and $50^{\circ} \mathrm{N}$. The corresponding reason will be shown in section 5 .

As stated earlier, winter accumulated GPCP precipitation anomalies for the four El Niño winters are also grouped into two parts: AR-group and non-AR-group. The composite for the two groups are shown in Figs. 5b and 5c. The pattern for AR-group (Fig. 5b) is similar to that of the total precipitation anomalies (Fig. 5a) and much likes that of ARs frequency anomalies except the region over southwestern America. Precipitation anomalies for AR-group contribute nearly $60 \%$ of the positive anomalies in the core region. They also determine almost half of negative ones over the middle basin between $40^{\circ}$ and $55^{\circ} \mathrm{N}$. It is also noticed that, the negative anomalies in total precipitation over the central Pacific between $20^{\circ}$ and $30^{\circ} \mathrm{N}$ are mostly due to non-AR-group, not AR-group.

Above analyses are based on the composition for the four $\mathrm{El}$ Niño events during 1996-2018. To increase the number of samples, we also calculated the composites of winter accumulated ERA-Interim precipitation anomalies and corresponding AR-group's 

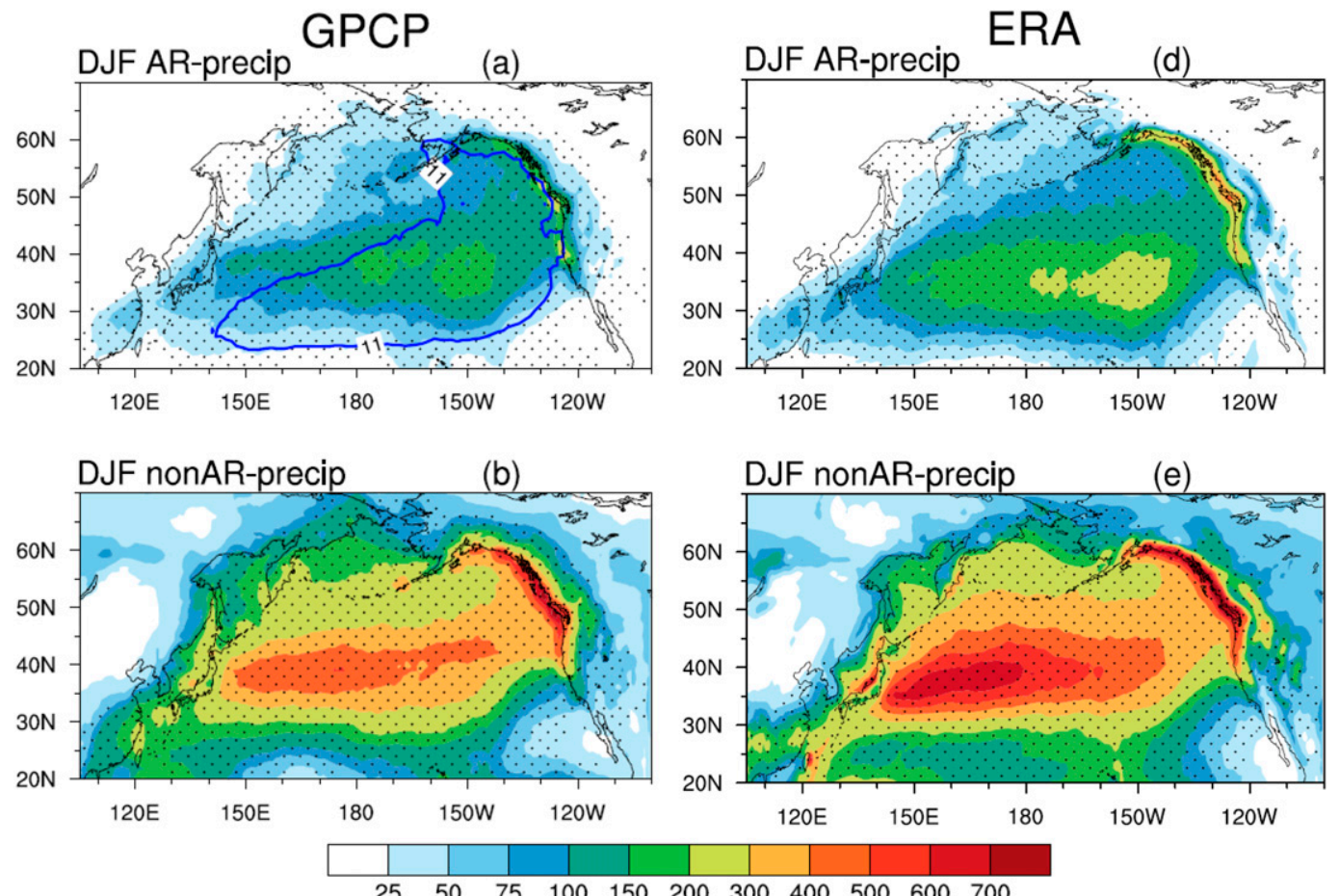

DJF AR-precip fraction

(c)
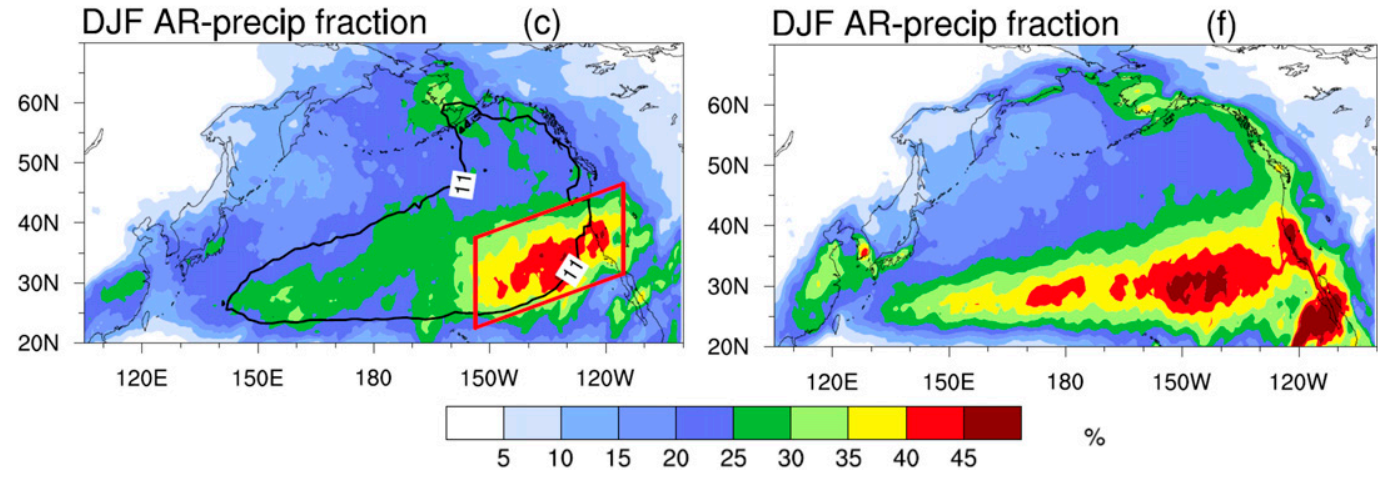

FIG. 2. (left) Climatological winter accumulated precipitation (shaded; mm winter ${ }^{-1}$ ) for (a) AR-group and (b) non-AR-group, and (c) AR precipitation fraction (percent of total precipitation) of GPCP during 1996-2018. (right) As in the left panels, but for ERA-Interim during 1979-2018. Dots indicate the areas where the differences between AR-group and non-AR-group are above $95 \%$ significance level. The red box in (c) indicates a core region with high ARs fraction (the same below).

and non-AR-group's contributions, and AR frequency anomaly for the nine El Niño events during 1979-2018 (right panels in Fig. 5). The composite of ERA-Interim precipitation during 19792018 bears some resemblance to that of GPCP during 1996-2018. The detectable difference is located over East Asia and its coastal waters for AR-group (Figs. 5b,f). ERA-Interim during 1979-2018 indicates that the positive precipitation anomalies over East Asia and its coastal waters are determined by non-AR-group but not AR-group. This result is because the AR frequency anomalies to the western part of the ARs main body during 1979-2018 (Fig. 5h) are not as robust as those during 1996-2018 (Fig. 5d). Despite of above discrepancy, the results around the core region (the red box region) during 1996-2018 are in consistent with those during 1979-2018.
The composites for the five La Niña winters during 19962018 are shown in the left panels of Fig. 6. It is noticeable that the pattern of GPCP precipitation anomalies during La Niña winters (Fig. 6a) is mostly opposite to that during El Niño winters (Fig. 5a). Especially, GPCP precipitation is significantly decreased over the eastern Pacific, and increased over the central Pacific (Fig. 6a). The pattern of ARs frequency anomalies during La Niña winters (Fig. 6d) is also nearly opposite to that during El Niño winters (Fig. 5d). But the areas above the significance level in Fig. 6d are relatively scattered. Most of the anomalous areas are not concentrated around the ARs main body region. Therefore, during the five La Niña winters, the magnitude of precipitation anomalies for AR-group (Fig. 6b) is robustly smaller than that for non-ARgroup (Fig. 6c). Non-AR-group determines mostly of the total 

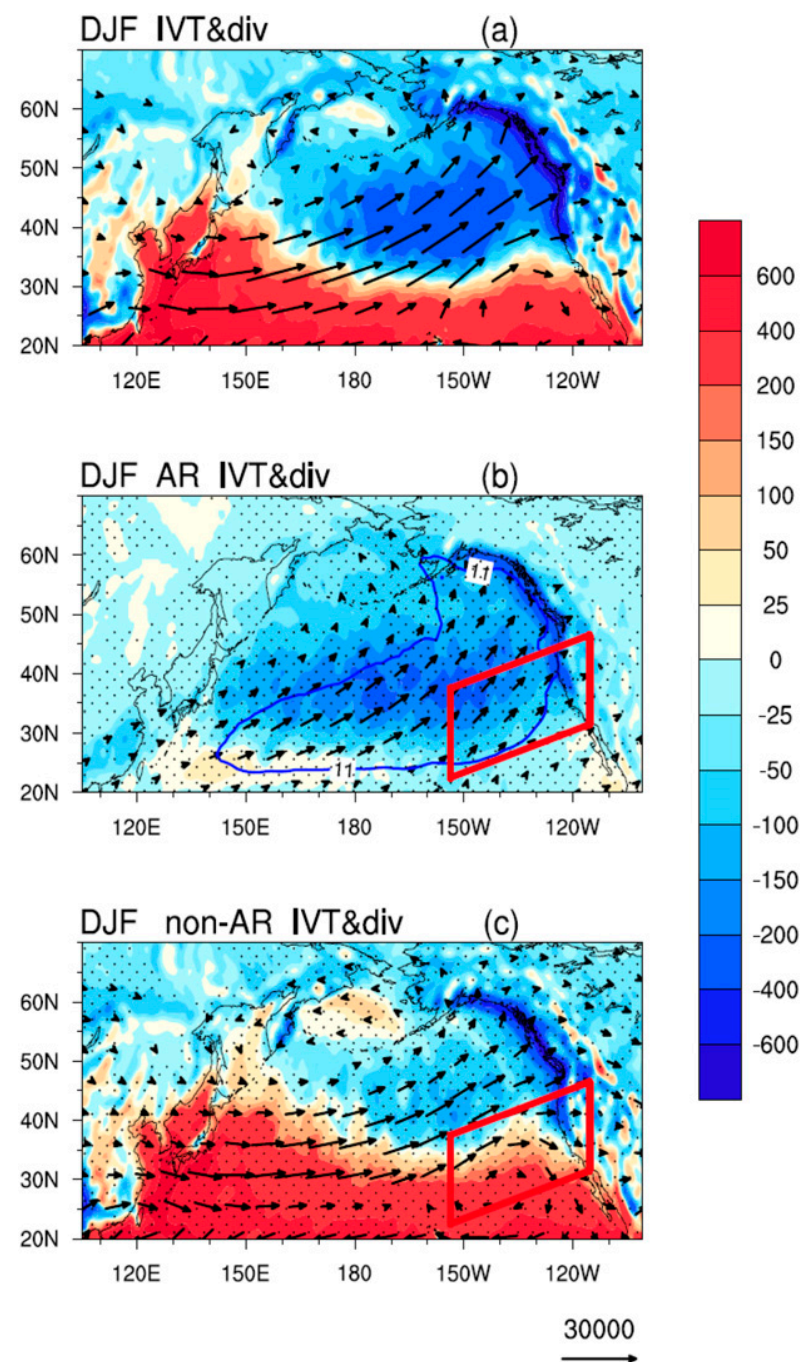

FIG. 3. (a) Climatological winter accumulated integrated vapor transport (IVT) (vector; $10^{5} \mathrm{~kg} \mathrm{~m}^{-1}$ winter $^{-1}$ ) and $\nabla \cdot$ IVT (shaded; mm winter ${ }^{-1}$ ) during 1996-2018. (b),(c) As in (a), but for AR-group and non-AR-group, respectively. Dots indicate the areas where the differences between AR-group and non-AR-group are above $95 \%$ significance level. Only values exceeding $2 \times 10^{8} \mathrm{~kg} \mathrm{~m}^{-1}$ winter $^{-1}$ are shown for IVT. The red box in (b) and (c) is as in Fig. 2c.

precipitation anomalies, except that over the eastern Pacific (the red box region) in which AR-group's contribution is nonnegligible.

The right panels in Fig. 6 are the same as the right panels in Fig. 5, but for the seven La Niña winters during 1979-2018. ERA-Interim shows a similar pattern of positive precipitation anomalies over the central Pacific and negative ones over the eastern Pacific as GPCP (Fig. 6e). Only the positive anomalies over the central Pacific in ERA-Interim occupy robustly larger area than those in GPCP. They are also largely contributed by non-AR-group (Fig. 6g). The pattern of AR frequency anomalies during 1979-2018 looks somewhat like that during 1996-2018, except that the decreasing around the core region during 1979-2018 (Fig. 6h) is more robust than that during 1996-2018 (Fig. 6d).

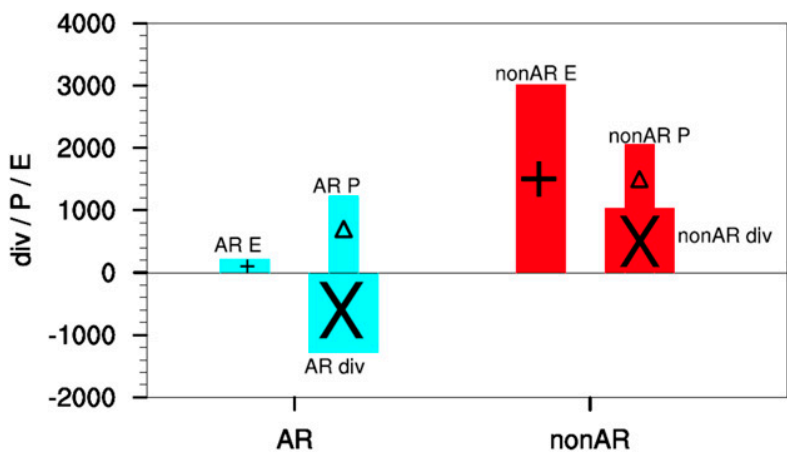

FIG. 4. Bar charts denoting climatological accumulated GPCP daily precipitation $P\left(\Delta ; \mathrm{mm} \mathrm{day}^{-1}\right)$, evaporation $E(+$; $\mathrm{mm} \mathrm{day}^{-1}$ ), and $\nabla \cdot$ IVT (div; $\times ; \mathrm{mm} \mathrm{day}^{-1}$ ) for all the AR grids (cyan bars) and the non-AR grids (red bars) in the red box of Fig. 2c during 1996-2018 winters.

The above analyses of Figs. 5 and 6 indicate that, the ENSOinduced precipitation and ARs frequency anomalies in the core region are significant and are basically consistent between GPCP during 1996-2018 and ERA-Interim during 1979-2018. Therefore, we will compare precipitation anomaly between AR-group and non-AR-group, by taking the core region as an example.

As mentioned above, for AR-group, the positive (negative) precipitation anomaly in the core region is accompanied by the increased (decreased) in situ AR frequency during El Niño (La Niña) winters. This means the moisture convergence anomaly associated with ARs should be responsible for the precipitation anomaly in the core region during ENSO winters. To substantiate the relationship, we plot similar bar charts as in Fig. 4 but for anomalous values during ENSO winters of 19962018 (Fig. 7). It is seen that, for AR-group, the increased $P$ in the core region is indeed attributed largely to the more in situ ARs and thus enhanced moisture convergence $\left[\left(\nabla \cdot \mathrm{IVT}^{\prime}<0\right]\right.$ during El Niño winters, and vice versa for La Niña winters.

For non-AR-group, the increased $P$ in the core region during El Niño winters is unequivocally attributed to the anomalous convergence of moisture transport $\left[(\nabla \cdot \text { IVT })^{\prime}<0\right]$ (Fig. 7a). This relationship is different from the climatological result shown in Fig. 4. In addition, for non-AR-group, the decreased evaporation from Earth's surface has a role of reducing in situ precipitation. Therefore, non-AR-group needs larger quantity of anomalous moisture convergence than AR-group to produce above-normal precipitation equivalent to AR-group.

During La Niña winters, the decreased $P$ in the core region for non-AR-group is partly due to the negative anomaly in $E$ and partly to the anomalous divergence of moisture transport $\left[(\nabla \cdot \text { IVT })^{\prime}>\right.$ $0)$ ]. However, the precipitation anomaly in the core region for nonAR-group is not as significant as that for AR-group (Figs. 6b,c). Thus, more La Niña samples are needed to verify the relationship among the three terms $(P, \nabla \cdot$ IVT, and $E)$ for non-AR-group.

\section{Decomposition of IVT and $\nabla \cdot$ IVT during ENSO winters}

The above investigation of the relationship between precipitation anomaly and $\nabla \cdot$ IVT anomaly is only confined to the 
GPCP
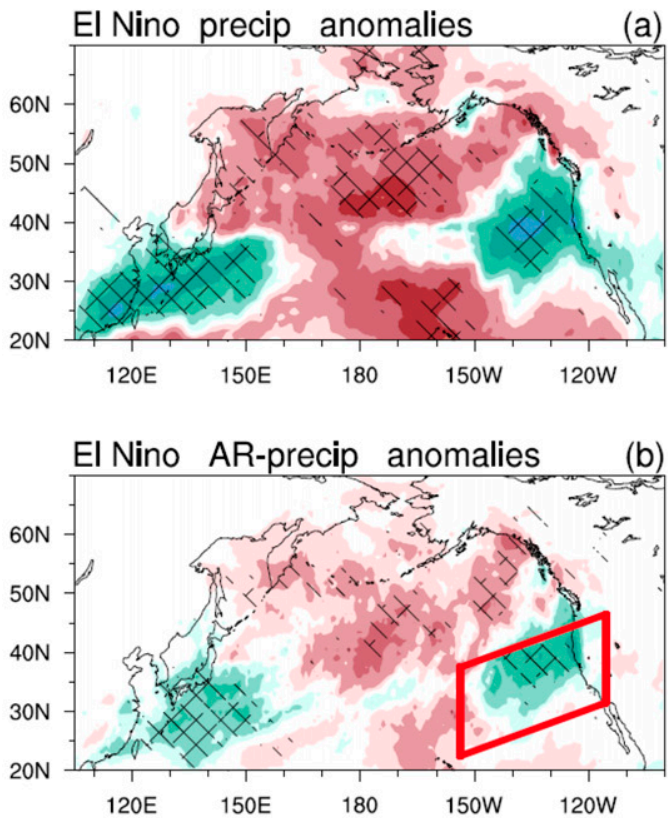

El Nino nonAR-precip anomalies (c)

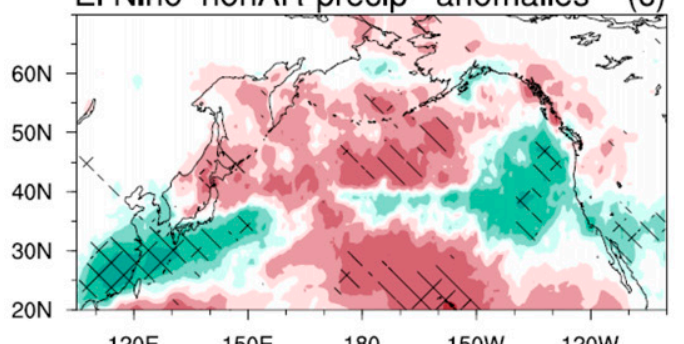

120E $\quad 150 \mathrm{E} \quad 180$

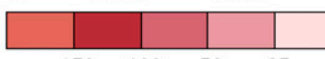

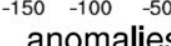

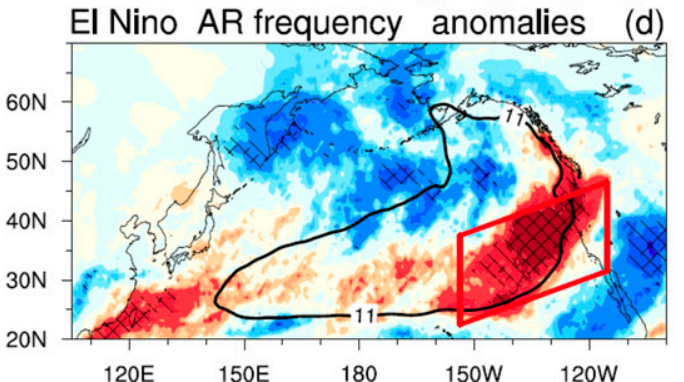

ERA
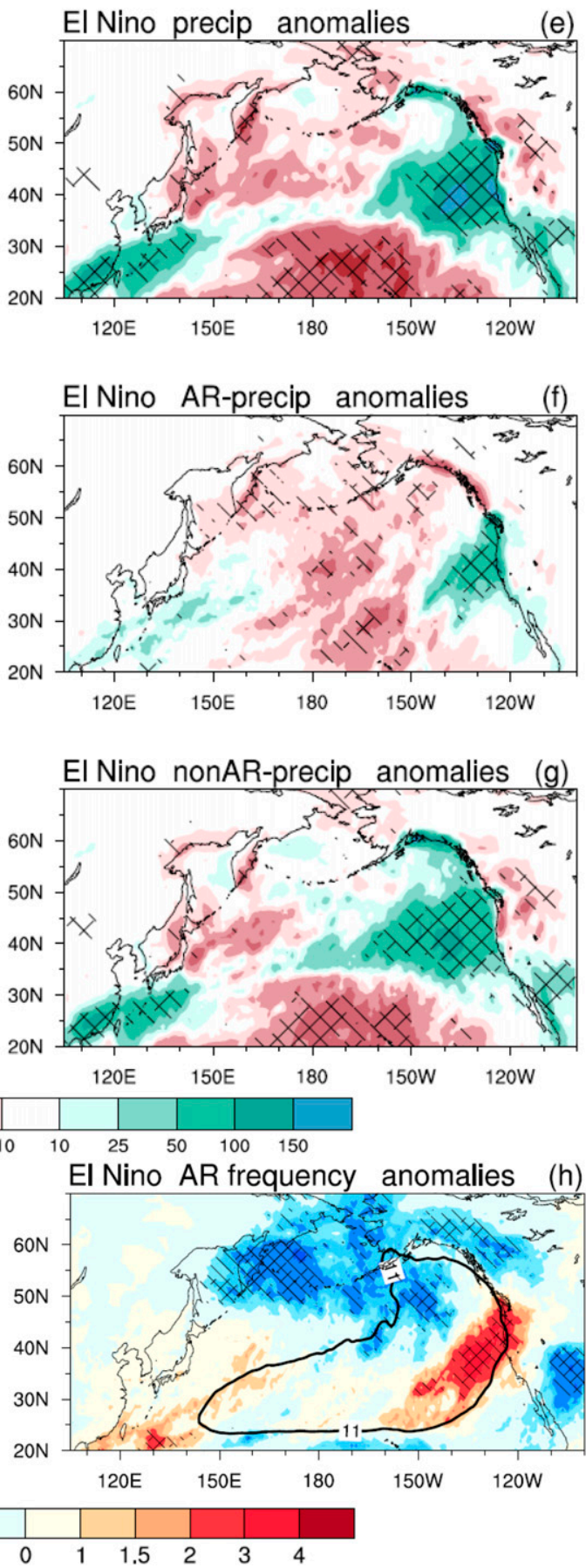

FIG. 5. (a) Composite anomalies in winter accumulated GPCP precipitation $\left(\mathrm{mm}\right.$ winter ${ }^{-1}$ ) and (d) AR frequency (\%) for the four El Niño winters during 1996-2018. (b),(c) As in (a), but for AR-group and non-AR-group, respectively. (e)-(h) As in (a)-(d), but for the nine El Niño winters during 1979-2018. The precipitation in (e) is from ERA-Interim. The left $(/)$ and right $(\backslash)$ oblique lines denote the areas exceeding $95 \%$ and $90 \%$ significance levels, respectively. The black contour in (d) and (h) indicates the climatological winter ARs frequency of $11 \%$. The red boxes in (b) and (d) are as in Fig. 2c. 


\section{GPCP}
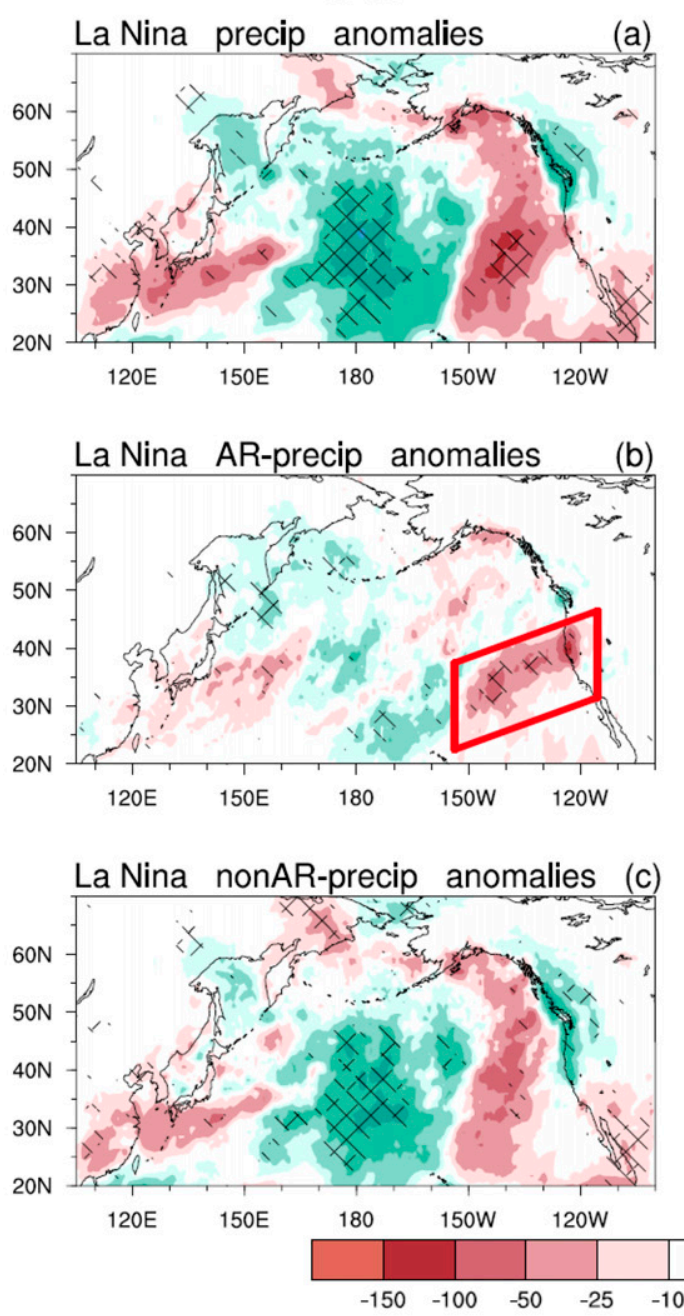
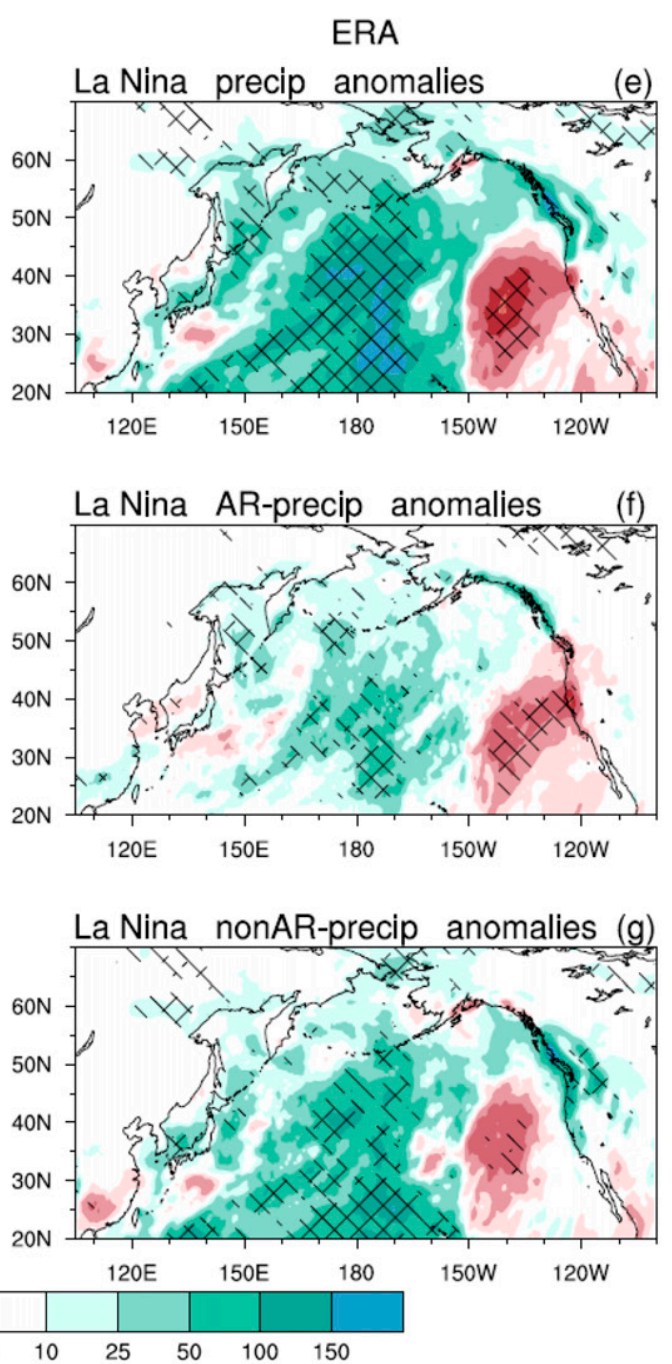

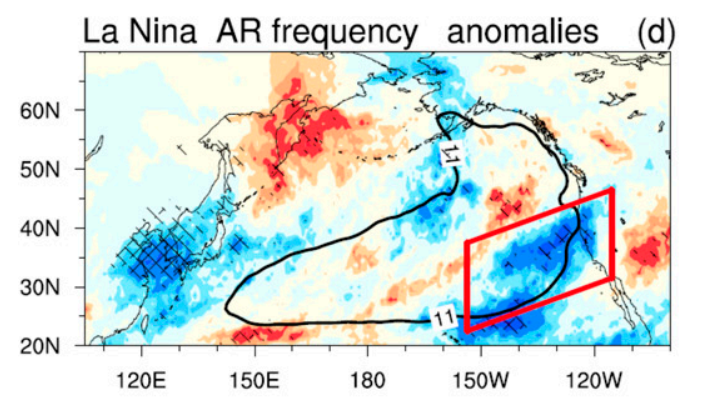

$(d)$

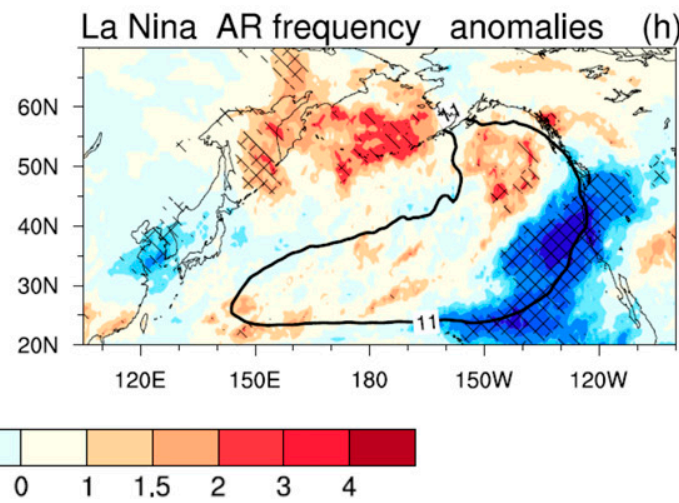

FIG. 6. As in Fig. 5, but (a)-(d) for the five La Niña winters during 1996-2018 and (e)-(h) for the seven La Niña winters during 1979-2018.

core region of the ARs' influence. In this section, we will show that, anomalies in IVT and $\nabla$. IVT are essential to anomalies in $P$ over the pan-North Pacific during ENSO winters. In particular, the relative contributions of different physical process involving wind fields and specific humidity to IVT and $\nabla$. IVT anomalies during ENSO winters are addressed in this section, based on the time-scale decomposition described in section $2 \mathrm{~d}$. For conciseness, only the results during 1996-2018 are shown in this section and next. 

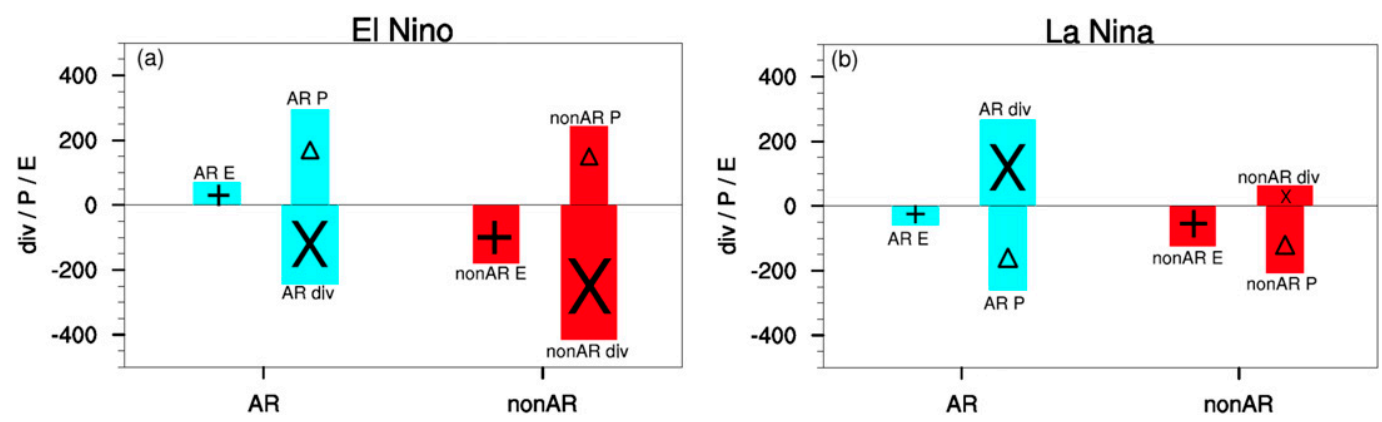

FIG. 7. (a) As in Fig. 4a, but for anomalous values during the four El Niño winter in 1996-2018. (b) As in (a), but for the five La Niña winter during 1996-2018.

Figure 8a shows composite of accumulated anomalies in IVT [the term T in Eq. (2)] and $\nabla$. IVT [the term T in expression (3)] for El Niño winters. The corresponding results for AR-group and non-AR-group are plotted in Figs. 8b and 8c.
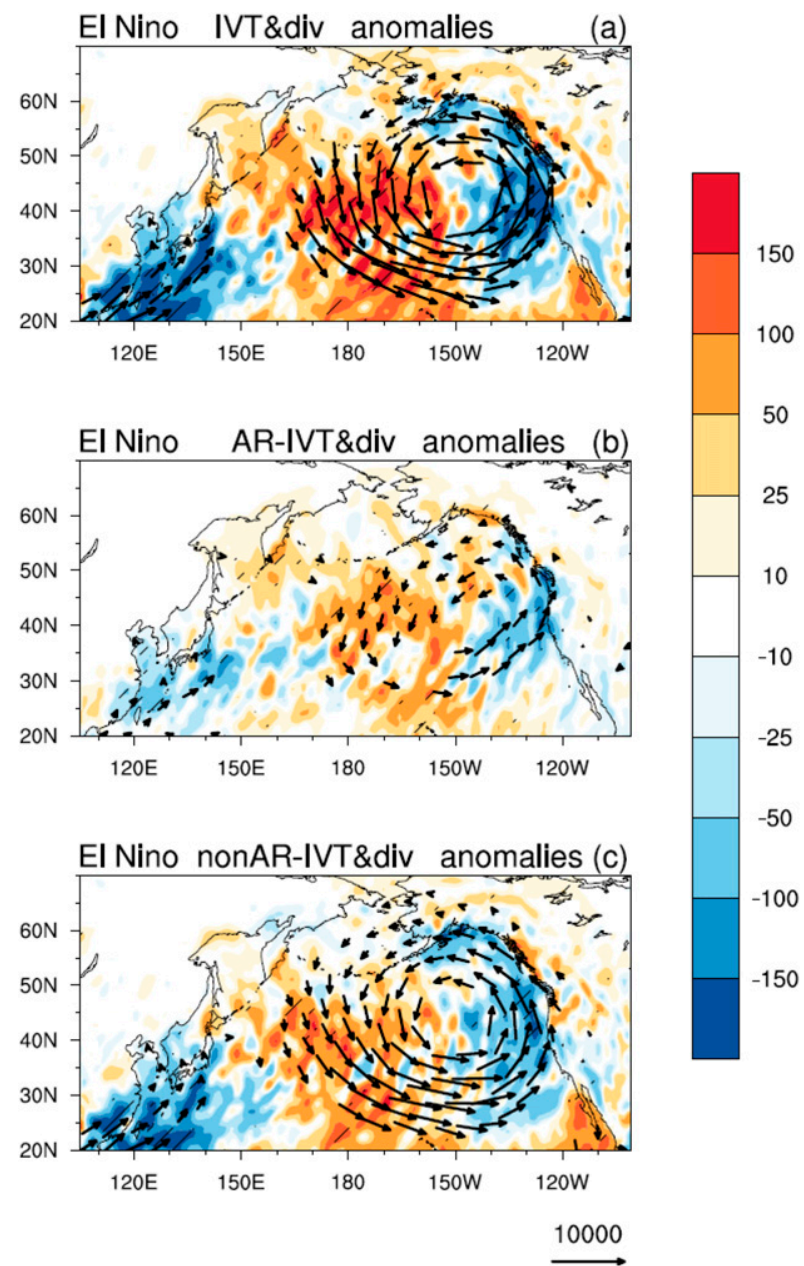

FIG. 8. (a) Composite anomalies in winter accumulated IVT (vector; only the areas above the $95 \%$ confidence level are shown; $10^{5} \mathrm{~kg} \mathrm{~m}^{-1}$ winter $^{-1}$ ) and $\nabla \cdot$ IVT (shaded; $\mathrm{mm}_{\text {winter }}{ }^{-1}$ ) for the four El Niño winters during 1996-2018. (b),(c) As in (a), but for AR-group and non-AR-group, respectively. The left oblique lines denote the areas exceeding the $95 \%$ significance level for $\nabla \cdot$ IVT.
During El Niño winters, an anomalous cyclonic transport is located over the central and the northeastern Pacific, and anomalous northeastward transport over East Asia and its coastal waters. The $\nabla$. IVT anomalies show an anomalous moisture source over the central basin and anomalous moisture sinks over East Asia and its coastal waters and near the North American west coast (Fig. 8a). Above pattern of $\nabla$. IVT anomalies bears close resemblance to the pattern of precipitation anomalies in Fig. 5a. Thus, anomalous convergence of water vapor transport over the western and the eastern Pacific is conducive to the increased in situ precipitation. Meanwhile, anomalous divergence of water vapor transport over the central basin contributes to the decreased in situ precipitation.

The patterns of IVT and $\nabla$. IVT anomalies for AR-group (Fig. 8b) and non-AR-group (Fig. 8c) are all alike those in Fig. 8a to a certain extent. For AR-group, the cyclonic transport anomaly over the central and the eastern Pacific intensifies the northeastward moisture transport over the eastern Pacific, and weakens the poleward moisture transport over the middle basin. Above IVT anomalies lead to the anomalies in AR frequency during El Niño winters shown in Fig. 5d. AR-group contributes around $35 \%$ of accumulated anomalous moisture sink in the core region. It also decides nearly $40 \%$ of anomalous moisture source over the middle basin between $35^{\circ}$ and $50^{\circ} \mathrm{N}$.

The three processes contributing to anomalies in IVT and $\nabla$. IVT, including the term A (dynamic process), the term B (thermodynamic process), and the term $\mathrm{C}$ (nonlinear process) during El Niño winters are calculated according to Eqs. (2) and (3), respectively. The upper panels in Fig. 9 plot the composite anomalies of the three terms for El Niño winters. The anomalous patterns of IVT and $\nabla$. IVT shown in Fig. 8 a are preliminarily decided by the term A and second by the term B. The amplitude of term $C$ is much smaller than those of terms $A$ and B. Namely, changes in the circulation mostly determine the anomalies in IVT and $\nabla$. IVT during El Niño winters, which is consistent with previous suggestion (Seager and Naik 2012; Seager et al. 2012; Kim et al. 2017). The middle and bottom panels in Fig. 9 are results for AR-group and non-AR-group, respectively. Similarly, the term $\mathrm{A}$ is the first important and the term $\mathrm{B}$ is the second.

In addition, it is found that the pattern of thermodynamic process (the term B) is somewhat opposite to that of dynamic process (the term A), and there is a small phase difference 

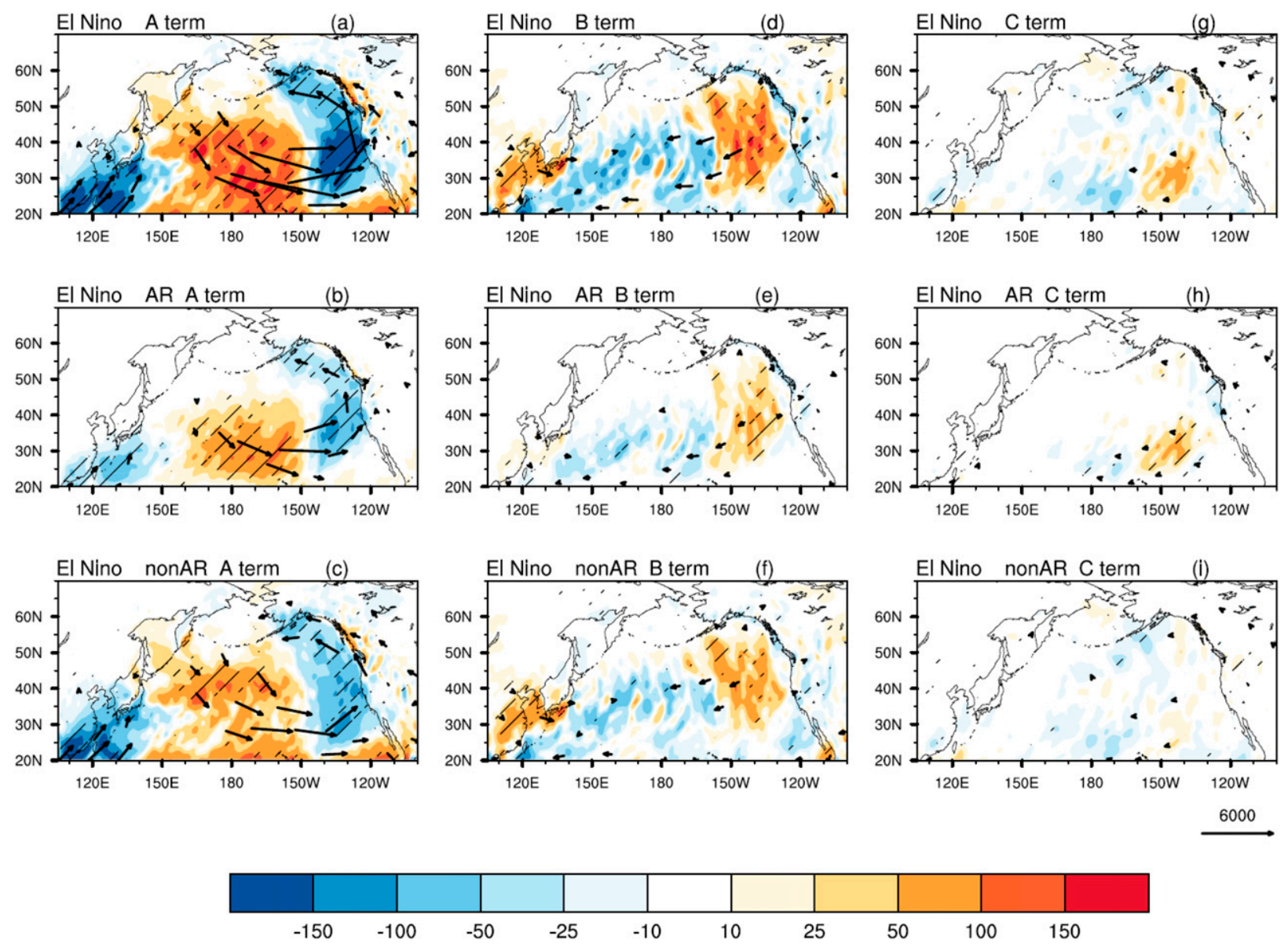

FIG. 9. (top) Composite anomalies in terms of (a) IVT_A (vector; only the areas above the $95 \%$ confidence level are shown; $10^{5} \mathrm{~kg} \mathrm{~m}^{-1}$

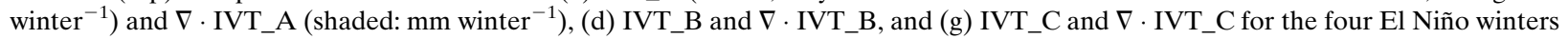
during 1996-2018. (middle),(bottom) As in the top panels, but for AR-group and non-AR-group, respectively. The left oblique lines denote the areas exceeding the $95 \%$ significance level for $\nabla \cdot$ IVT.

between the two patterns during El Niño winters. Therefore, the effect of thermodynamic process (the term B) is to slightly weaken the dynamic process (the term A), and to blur the boundary between the positive and negative regions in the pattern of term A.

Figure 10 plots the composite for La Niña winters. The total IVT and $\nabla \cdot$ IVT anomalies during La Niña winters (Fig. 10a) show almost the same patterns but with opposite sign of those for El Niño winters (Fig. 8a). The anomalous moisture source over the western and eastern Pacific, and the anomalous moisture sink over the central Pacific (Fig. 10a) are conducive to the decreased and increased in situ precipitation, respectively (Fig. 6a). The total IVT and $\nabla$. IVT anomalies are mostly contributed by non-AR-group, except that over the eastern Pacific.

The three terms (A, B, and C) are also computed for La Niña winters (Fig. 11). Similar to what is seen during El Niño winters, the term A (dynamic process) is essential to the IVT and $\nabla \cdot$ IVT anomalies. The term $\mathrm{C}$ is also much smaller than the terms $\mathrm{A}$ and B during La Niña winters. We can see that the thermodynamic process (the term B) also acts to slightly weaken the dynamic process (the term A), just like those during El Niño winters. Different from the results during El Niño winters, the pattern of term B (thermodynamic process) exhibits a nearly quadrature relation with that of the term A, no matter for AR-group or nonAR-group during La Niña winters. For example, the longitude position (about $175^{\circ} \mathrm{W}$ ) of the negative centers of the term $\mathrm{A}$ in Fig. 11a is the dividing longitude between the left-positive and right-negative centers of the term B in Fig. 11d. The pattern of term A during La Niña winters is almost opposite to its counterpart during El Niño winters. Therefore, the term B (thermodynamic process) has a role in causing asymmetric features of IVT and $\nabla \cdot$ IVT anomalies between El Niño and La Niña. Due to the dominant role of the term $\mathrm{A}$, the nonsymmetric effect caused by the term B is finite.

\section{Extreme precipitation}

In this section, we will show the extreme precipitation and its relationship with IVT $(\nabla \cdot$ IVT) on climatological aspect and during ENSO winters. The upper panels in Fig. 12 depict climatological winter accumulated precipitation and total days 


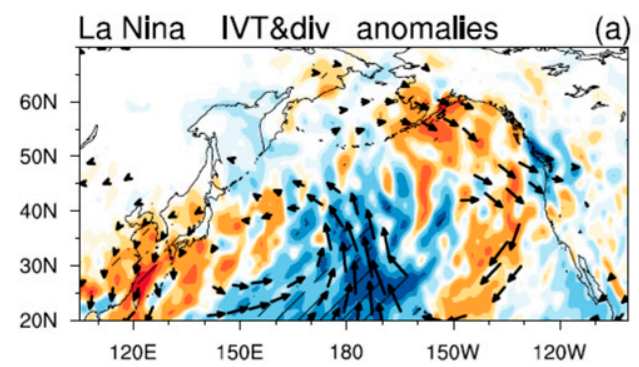

(a)
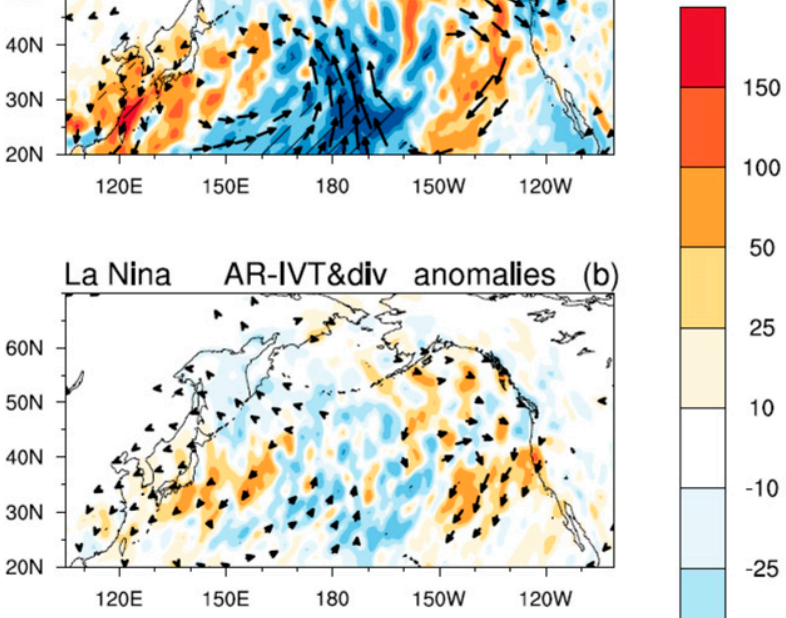

150

50

25

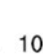

10

$-10$

$-25$

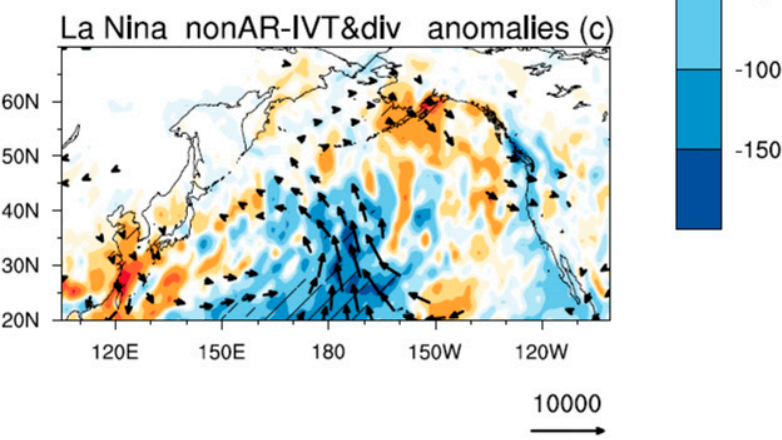

FIG. 10. As in Fig. 8, but for the five La Niña winters during 1996-2018.

of 2-day EPEs and the corresponding accumulated IVT and $\nabla \cdot$ IVT of 2-day EPEs, respectively. The second and third panels are the results for AR-group and AR-group fraction, respectively. It is seen that, the patterns of winter accumulated extreme precipitation and the corresponding total days (Figs. 12a,d) closely resemble that of the climatological winter accumulated precipitation (Fig. 1a). The patterns for AR-group (Figs. 12b,e) are alike that in Fig. 2a. AR-group contributes more than $50 \%$ of the total precipitation and total days of 2-day EPEs to the east of the date line. The fraction is up to $70 \%$ or above within the core region (Figs. 12c,f).

The direction of climatological total IVT for EPEs shows considerable eastward and northeastward transports over the western Pacific and poleward transports over the central and northeastern Pacific (Fig. 12g). The corresponding total $\nabla \cdot$ IVT shows a huge moisture sink over the whole basin. Two moisture sink centers of 2-day EPEs are seen over the middle basin between $30^{\circ}$ and $45^{\circ} \mathrm{N}$ and along the west coast, respectively, contributing directly to the in situ extreme precipitation shown in Fig. 12a. The above pattern of total IVT and $\nabla \cdot$ IVT for 2-day EPEs are largely attributed to AR-group
(Fig. 12h). The very high fraction of AR-group (Fig. 12i) indicates that, climatologically, the AR-related extreme precipitation is overwhelmingly caused by AR-produced huge moisture sink over most of the basin, especially over the core region (the red box region).

ENSO also affects the variation of extreme precipitation over the pan-North Pacific region. The upper panels in Fig. 13 plot composite anomalies in accumulated precipitation and total days, as well as IVT and $\nabla$. IVT for 2-day EPEs for the four El Niño winters during 1996-2018, respectively. The extreme precipitation anomalies display a positive-negativepositive structure spanning from East Asia and its coastal waters to the eastern Pacific (Fig. 13a). The total number of 2-day EPEs is increased about 1 event per winter over the eastern Pacific and decreased about 1 event per winter over the central Pacific between $20^{\circ}$ and $30^{\circ} \mathrm{N}$. The extreme precipitation anomalies are closely related to their corresponding anomalies of IVT and $\nabla$. IVT (Fig. 13e). Compared with that of climatology (Fig. 12g), much stronger northward and northeastward transports and increased moisture sinks are seen over eastern Asia and its coastal waters, and the eastern Pacific. Meanwhile, decreased poleward transports and decreased moisture sink are observed over the middle basin (Fig. 13e). Therefore, the increased moisture sink over the western and the eastern Pacific in Fig. 13e fuels in situ extreme precipitation in Fig. 13a. While, the decreased moisture sink over the central basin reduces the in situ frequency of extreme event and the corresponding total extreme precipitation.

The second panels in Fig. 13 show the results for AR-group. Obviously, AR-group has robust contributions to the total anomalies over the western and eastern Pacific, and middle basin, due to the in situ AR frequency anomalies during El Niño winters shown in Fig. 5d. There is no robust change in ARs frequency over the central Pacific between $20^{\circ}$ and $30^{\circ} \mathrm{N}$ during El Niño winters (Fig. 5d). Therefore, the increased extreme precipitation and the corresponding total days in that region are contributed by non-AR-group.

The patterns of anomalies in accumulated precipitation, IVT and $\nabla$. IVT of 2-day EPEs over the North Pacific during La Niña winters are analogous to their El Niño counterpart but with opposite sign. Thus, we will not show figures and only describe briefly the conclusion. During La Niña winters, a significantly increased total precipitation for 2-day EPEs is seen over the central basin and a slightly decreased one over the eastern Pacific. These anomalies are also due to an enhanced and a reduced in situ moisture sinks of 2-day EPEs, respectively (figure omitted). AR-group only has a certain contribute to the decreased extreme precipitation and the corresponding $\nabla \cdot$ IVT anomaly over the eastern Pacific. This is because the reduced in situ AR frequency during La Niña winters shown in Fig. 6d.

\section{Conclusions and discussion}

\section{a. Conclusions}

This study investigates the influence of ARs on winter precipitation for climatology and during ENSO condition over the 

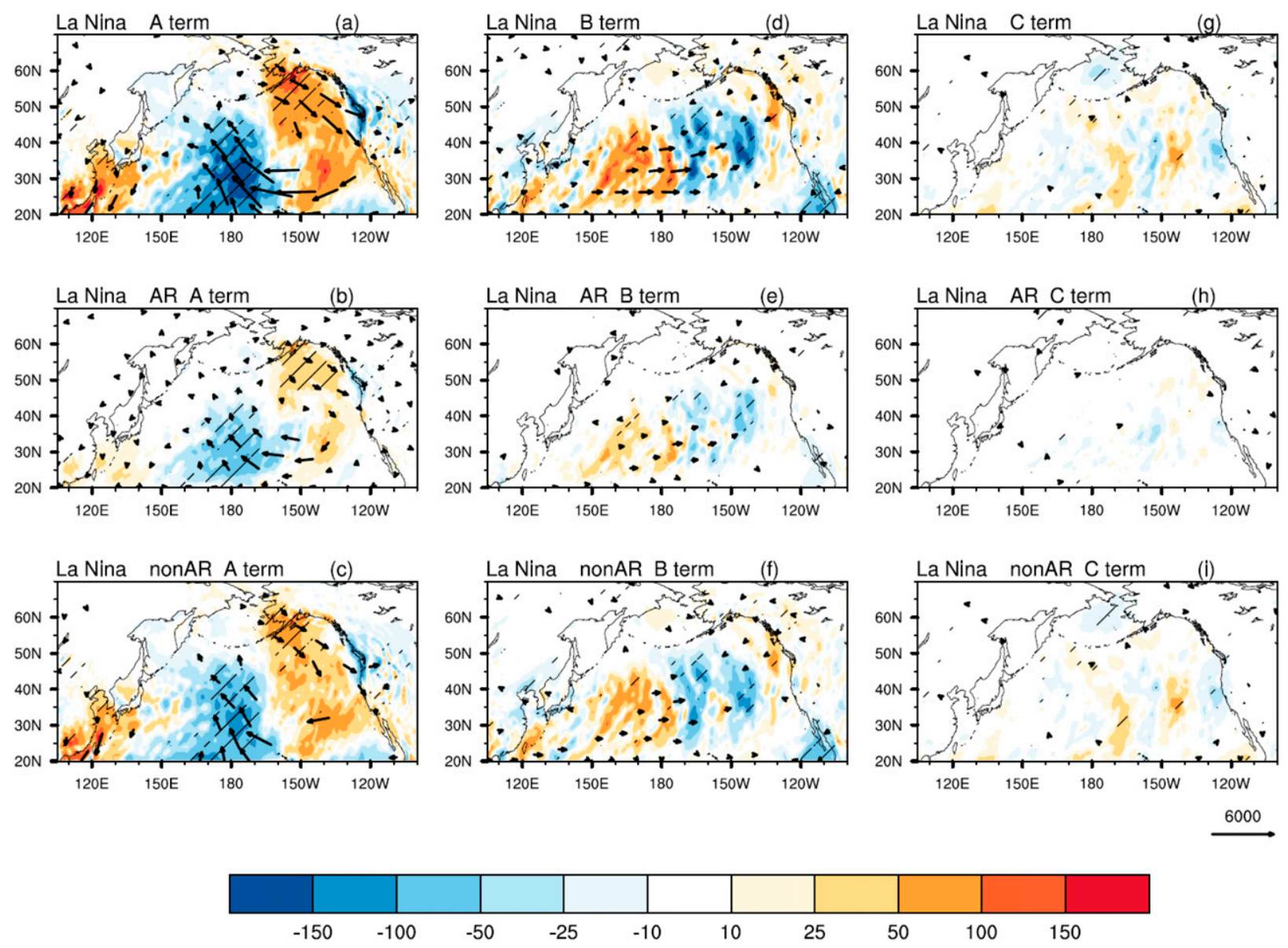

FIG. 11. As in Fig. 9, but for the five La Niña winters during 1996-2018.

pan-North Pacific region, by using statistical analysis of the fields from GPCP (1996-2018) and ERA-Interim (1979-2018) daily data. We divided total values of precipitation, IVT and $\nabla \cdot$ IVT into AR-group and non-AR-group. We underscored the ARs' influence on total precipitation and extreme precipitation by evaluating and comparing the contributions of the two groups to precipitation and water vapor transport.

The main body of climatological wintertime ARs is located over the central Pacific and curves northeastward to the northwest coast. Precipitation for AR-group is concentrated over the central and northeastern Pacific and along the northwest coast. AR-group contributes about $30 \%-45 \%$ of the climatological total winter precipitation, and up to $70 \%$ of total precipitation and total days of 2-day EPE over the eastern Pacific and along the west coast between $25^{\circ}$ and $45^{\circ} \mathrm{N}$. We picked the above area as the core region of the ARs' influence on precipitation.

Our results show that, climatologically, AR-group produces a moisture $\sin \mathrm{k}(\nabla \cdot$ IVT $<0)$ occupying almost the whole basin, while non-AR-group demonstrates a moisture sink only over the northeastern Pacific north of $35^{\circ} \mathrm{N}$. Thus, in the core region, the relationship between precipitation and moisture convergence for AR-group is different from that for non-AR-group. ARgroup's precipitation in the core region is mostly determined by the AR-produced moisture convergence. In contrast, for nonAR-group, the divergence of moisture transport $(\nabla \cdot \mathrm{IVT}>0)$ in the core region is unfavorable to in situ precipitation. Non-ARgroup's precipitation in the core region is attributed to evaporation from the earth surface.

We further investigated the AR influence on total and extreme precipitation during ENSO winters. During El Niño winters, the total precipitation anomalies show a tripolar pattern of a positive center over East Asia and its coastal waters, a negative one over the central Pacific and another positive one over the eastern Pacific and the coastal areas of California. The AR frequency is increased in the core region, and decreased over the middle basin between $40^{\circ}$ and $50^{\circ} \mathrm{N}$. AR-group contributes nearly $60 \%$ of the positive precipitation anomalies in the core region. Besides, almost half of negative ones over the middle basin between $40^{\circ}$ and $55^{\circ} \mathrm{N}$ is attributed to AR-group. During El Niño winters, the anomalous patterns in total extreme precipitation, along with its total days are mostly determined by AR-group. During La Niña winters, AR-group's contribution (about $50 \%$ of the negative precipitation anomalies) is robust only around the core region.

During El Niño winters, anomalous moisture sinks over the western and the eastern Pacific are conducive to the increased 

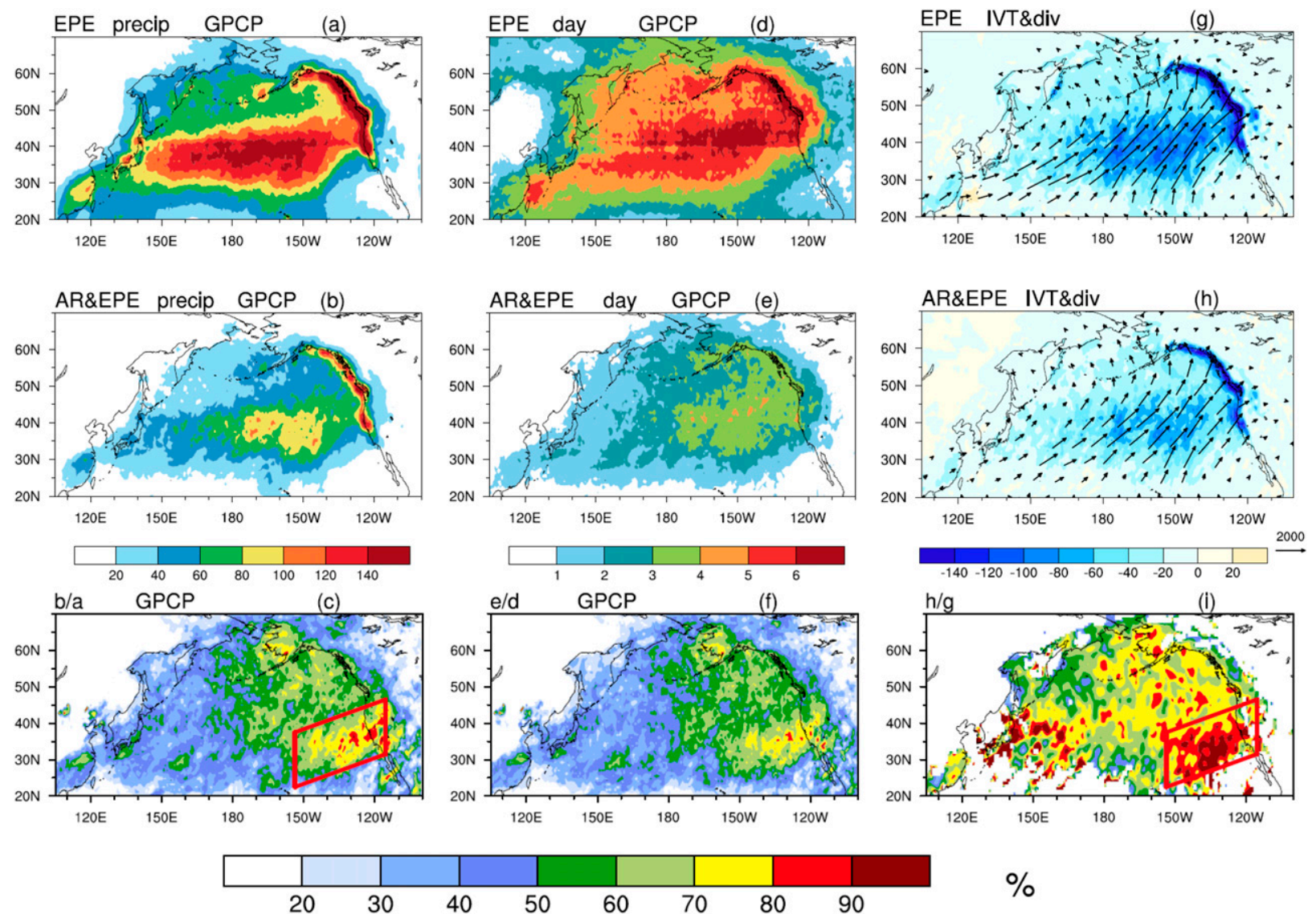

$\%$

FIG. 12. (a) Climatological winter accumulated GPCP precipitation ( $\mathrm{mm}_{\text {winter }}^{-1}$; $\geq 95$ th percentile daily precipitation), (d) total days

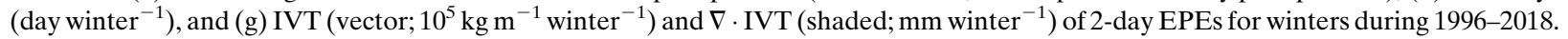
(b), (e),(h) As in (a),(d),(g), but for AR-group. (c) Ratio of (b) to (a), (f) ratio of (e) to (d), and (i) ratio of (h) to (g).

in situ precipitation. Meanwhile, anomalous moisture source over the central basin contributes to the decreased in situ precipitation. Similar relation is also seen during La Niña winters. ARs play a more essential role in the total moisture source and sink anomalies during El Niño winters than during La Niña winters. AR-group contributes around $35 \%$ of accumulated anomalous moisture sink in the core region. It also decides nearly $40 \%$ of anomalous moisture source over the middle basin between $35^{\circ}$ and $50^{\circ} \mathrm{N}$.

Based on a time-scale decomposition, it is showed that, the total IVT and $\nabla$. IVT anomalies are primarily decided by changes in wind fields (dynamic process) and second by changes in moisture (thermodynamic process), whether in ARgroup or non-AR-group. In addition, changes in moisture act to slightly weaken the dynamic process and to cause asymmetric features of IVT and $\nabla \cdot$ IVT anomalies between El Niño and La Niña but with limited effects. The nonlinear process is much smaller than above processes.

\section{b. Discussion}

Previous studies showed that ENSO-related precipitation anomalies vary widely from episode to episode (e.g., Ropelewski and Halpert 1987; D. Chen et al. 2019). Therefore, dataset with longer period and more ENSO cases are needed to confirm the ARs' influence. On the other hand, the ARs' influence on precipitation anomalies is also different during central Pacific (CP) and eastern Pacific (EP) El Niño events (Kim and Alexander 2015; Kim et al. 2017). Thus, the ARs' impact on moisture transport and precipitation in the pan-North Pacific region should be investigated further via separating $\mathrm{CP}$ and $\mathrm{EP}$ El Niño events.

We only focus on the influence of winter ARs over the panNorth Pacific region. ARs are global phenomena with a large impact on regional hydrological events in many locations (Guan and Waliser 2015; Mundhenk et al. 2016). In addition, water vapor increases and circulation patterns change in a warming climate. These changes may influence ARs (Payne and Magnusdottir 2015; Hagos et al. 2016; Tan et al. 2020). Above issues require further exploration in the future.

Acknowledgments. The authors wish to thank Guan and Waliser for providing the source code of the AR detection algorithm. We also thank the reviewers for their useful comments, which helped to improve this manuscript. The ERAInterim daily data are downloaded from http://apps.ecmwf. int/datasets/. The GPCP daily data are downloaded from 

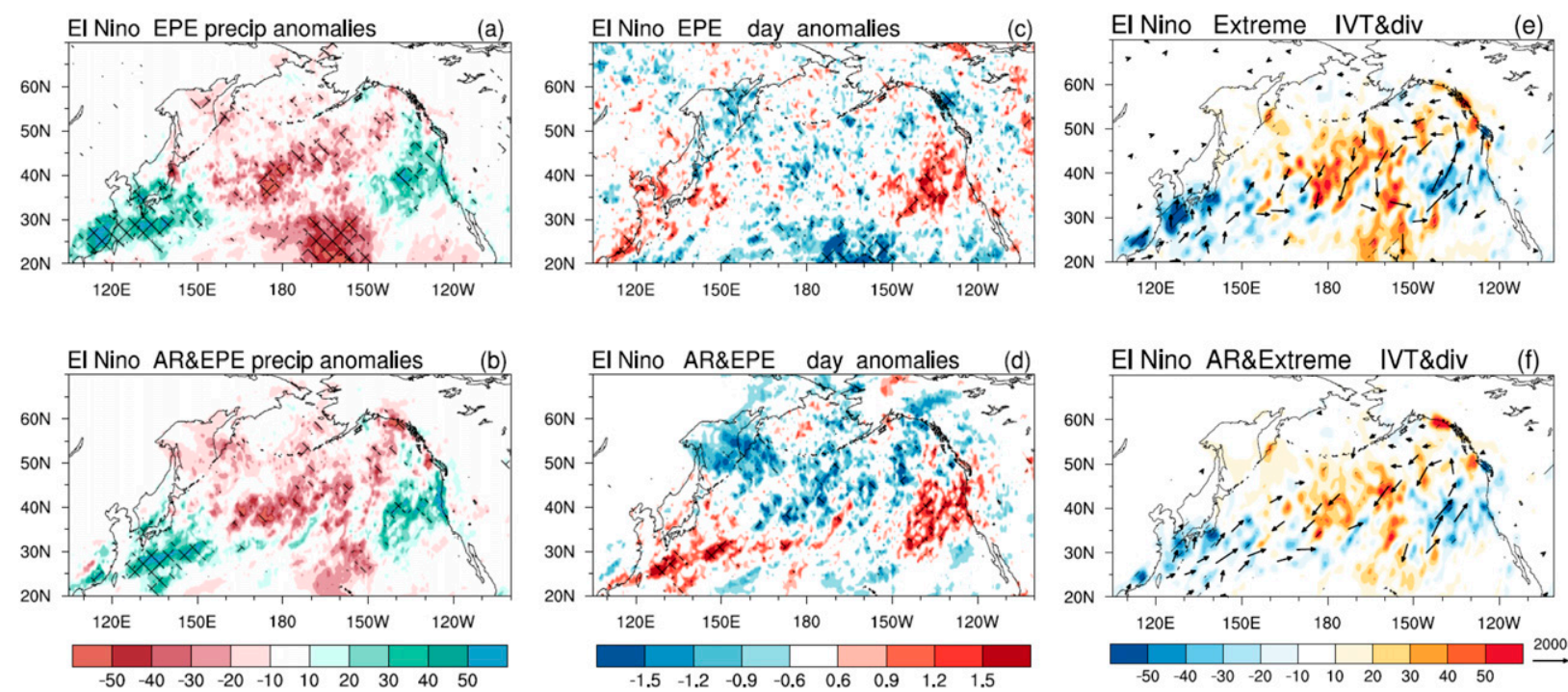

FIG. 13. (a) Composite anomalies in accumulated GPCP precipitation (mm winter $\left.{ }^{-1}\right)$, (c) total days (day winter ${ }^{-1}$ ), and (e) accumulated IVT (vector; $10^{5} \mathrm{~kg} \mathrm{~m}^{-1}$ winter $^{-1}$ ) and $\nabla \cdot$ IVT (shaded; $\mathrm{mm}_{\text {winter }}^{-1}$ ) of 2-day EPEs for the four El Niño winters during 1996-2018. (b),(d),(f) As in (a),(c),(e), but for AR-group. The left (/) and right ( $\backslash$ ) oblique lines denote the areas exceeding $95 \%$ and $90 \%$ significance levels, respectively.

http://eagle1.umd.edu/GPCP_CDR/Daily_Data. The Niño-3.4 index is downloaded from http://www.cpc.ncep.noaa.gov/data/ indices/. This work was jointly supported by the National Natural Science foundation of China under Grants 41621005, the National Key R\&D Program of China (Grants 2018YFC1505903), and the Special Fund for Meteorology Research in the Public Interest (Grant GYHY201106017).

\section{REFERENCES}

Brands, S., J. M. Gutiérrez, and D. San-Martín, 2017: Twentiethcentury atmospheric river activity along the west coasts of Europe and North America: Algorithm formulation, reanalysis uncertainty and links to atmospheric circulation patterns. Climate Dyn., 48, 2771-2795, https://doi.org/10.1007/ s00382-016-3095-6.

Brown, D. P., and A. C. Comrie, 2004: A winter precipitation 'dipole' in the western United States associated with multidecadal ENSO variability. Geophys. Res. Lett., 31, L09203, https://doi.org/10.1029/2003GL018726.

Cayan, D. R., K. T. Redmond, and L. G. Riddle, 1999: ENSO and hydrologic extremes in the western United States. J. Climate, 12, 2881-2893, https://doi.org/10.1175/1520-0442(1999)012<2881: EAHEIT > 2.0.CO;2.

Chen, D., Y. Gao, and H. J. Wang, 2019: Why was the August rainfall pattern in the east Asia-Pacific Ocean region in 2016 different from that in 1998 under a similar preceding El Niño background? J. Climate, 32, 5785-5797, https://doi.org/10.1175/ JCLI-D-18-0589.1.

Chen, G., J. Norries, J. D. Neelin, J. Lu, L. R. Leung, and K. Sakaguchi, 2019: Thermodynamic and dynamic mechanisms for hydrological cycle intensification over the full probability distribution of precipitation events. J. Atmos. Sci., 76, 497-516, https://doi.org/10.1175/JAS-D-18-0067.1.

Chen, J., Z. Wen, R. Wu, Z. Chen, and P. Zhao, 2014: Interdecadal changes in the relationship between southern China winter-spring precipitation and ENSO. Climate Dyn., 43, 1327-1338, https:// doi.org/10.1007/s00382-013-1947-x.

Chen, Q., H. Hu, X. Ren, and X.-Q. Yang, 2019: Numerical simulation of midlatitude upper-level zonal wind response to the change of North Pacific subtropical front strength. J. Geophys. Res. Atmos., 124, 4891-4912, https://doi.org/10.1029/2018JD029589.

Chen, T.-C., W.-R. Huang, and E. S. Takle, 2004: Annual variation of midlatitude precipitation. J. Climate, 17, 4291-4298, https:// doi.org/10.1175/JCLI3201.1.

Chervin, R. M., and S. H. Schneider, 1976: On determining the statistical significance of climate experiments with general circulation models. J. Atmos. Sci., 33, 405-412, https://doi.org/ 10.1175/1520-0469(1976)033<0405:ODTSSO > 2.0.CO;2.

Chou, C., L.-F. Huang, J.-Y. Tu, L. Tseng, and Y.-C. Hsueh, 2009: El Niño impacts on precipitation in the western North PacificEast Asian sector. J. Climate, 22, 2039-2057, https://doi.org/ 10.1175/2008JCLI2649.1.

Dai, A., and T. M. L. Wigley, 2000: Global patterns of ENSOinduced precipitation. Geophys. Res. Lett., 27, 1283-1286, https://doi.org/10.1029/1999GL011140.

Dee, D. P., and Coauthors, 2011: The ERA-Interim reanalysis: Configuration and performance of the data assimilation system. Quart. J. Roy. Meteor. Soc., 137, 553-597, https://doi.org/ 10.1002/qj.828.

DeFlorio, M. J., D. E. Waliser, B. Guan, D. A. Lavers, F. M. Ralph, and F. Vitart, 2018: Global assessment of atmospheric river prediction skill. J. Hydrometeor., 19, 409-426, https://doi.org/ 10.1175/JHM-D-17-0135.1.

Deser, C., I. R. Simpson, A. S. Phillips, and K. A. Mckinnon, 2018: How well do we know ENSO's climate impacts over North America, and how do we evaluate models accordingly? J. Climate, 31, 4991-5014, https://doi.org/10.1175/JCLI-D-170783.1.

Dettinger, M. D., 2013: Atmospheric rivers as drought busters on the U.S. West Coast. J. Hydrometeor., 14, 1721-1732, https:// doi.org/10.1175/JHM-D-13-02.1. 
F. M. Ralph, T. Das, P. J. Neiman, and D. R. Cayan, 2011: Atmospheric rivers, floods and the water resources of California. Water, 3, 445-478, https://doi.org/10.3390/w3020445.

Eldardiry, H., A. Mahmood, X.-D. Chen, F. Hossain, and B. Nijssen, 2019: Atmospheric river-induced precipitation and snowpack during the western United States cold season. J. Hydrometeor., 20, 613-630, https://doi.org/10.1175/JHM-D-18-0228.1.

Feng, J., L. Wang, W. Chen, S. Fong, and K. Leong, 2010: Different impacts of two types of Pacific Ocean warming on Southeast Asian rainfall during boreal winter. J. Geophys. Res., 115, D24122, https://doi.org/10.1029/2010JD014761.

Gimeno, L., and Coauthors, 2016: Major mechanisms of atmospheric moisture transport and their role in extreme precipitation events. Annu. Rev. Environ. Resour., 41, 117-141, https://doi.org/10.1146/annurev-environ-110615-085558.

Guan, B., and D. E. Waliser, 2015: Detection of atmospheric rivers: Evaluation and application of an algorithm for global studies. J. Geophys. Res. Atmos., 120, 12 514-12 535, https://doi.org/ 10.1002/2015JD024257.

- , N. P. Molotch, D. E. Waliser, E. J. Fetzer, and P. J. Neiman, 2010: Extreme snowfall events linked to atmospheric rivers and surface air temperature via satellite measurements. Geophys. Res. Lett., 37, L20401, https://doi.org/10.1029/2010GL044696.

_ D. E. Waliser, and F. M. Ralph, 2018: An intercomparison between reanalysis and dropsonde observations of the total water vapor transport in individual atmospheric rivers. J. Hydrometeor., 19, 321-337, https://doi.org/10.1175/JHM-D-17-0114.1.

Hagos, S. M., L. R. Leung, J.-H. Yoon, J. Lu, and Y. Gao, 2016: A projection of changes in landfalling atmospheric river frequency and extreme precipitation over western North America from the large ensemble CESM simulations. Geophys. Res. Lett., 43, 1357-1363, https://doi.org/10.1002/2015GL067392.

Huffman, G. J., R. F. Adler, M. M. Morrissey, D. T. Bolvin, S. Curtis, R. Joyce, B. McGavock, and J. Susskind, 2001: Global precipitation at one-degree daily resolution from multisatellite observations. J. Hydrometeor., 2, 36-50, https://doi.org/10.1175/1525-7541(2001)002<0036:GPAODD > 2.0.CO;2.

Kamae, Y., W. Mei, S.-P. Xie, M. Naoi, and H. Ueda, 2017: Atmospheric rivers over the northwestern Pacific: Climatology and interannual variability. J. Climate, 30, 5605-5619, https:// doi.org/10.1175/JCLI-D-16-0875.1.

Kenyon, J., and G. C. Hegerl, 2010: Influence of modes of climate variability on global precipitation extreme. J. Climate, $\mathbf{2 3}$ 6248-6262, https://doi.org/10.1175/2010JCLI3617.1.

Kim, H.-M., and M. A. Alexander, 2015: ENSO's modulation of water vapor transport over the Pacific-North American region. J. Climate, 28, 3846-3856, https://doi.org/10.1175/JCLID-14-00725.1.

_- Y. Zhou, and M. A. Alexander, 2017: Changes in atmospheric rivers and moisture transport over the Northeast Pacific and western North America in response to ENSO diversity. Climate Dyn., 52, 7375-7388, https://doi.org/10.1007/s00382-017-3598-9.

Kim, J., D. E. Waliser, P. J. Neiman, B. Guan, J.-M. Ryoo, and G. A. Wick, 2013: Effects of atmospheric river landfalls on the cold season precipitation in California. Climate Dyn., 40, 465474, https://doi.org/10.1007/s00382-012-1322-3.

Larkin, N. K., and D. E. Harrison, 2005: Global seasonal temperature and precipitation anomalies during El Niño autumn and winter. Geophys. Res. Lett., 32, L16705, https://doi.org/10.1029/ 2005 GL022860.

Lavers, D. A., and G. Villarini, 2015: The contribution of atmospheric rivers to precipitation in Europe and the United States.
J. Hydrol., 522, 382-390, https://doi.org/10.1016/j.jhydrol. 2014.12.010.

Leung, L. R., and Y. Qian, 2009: Atmospheric rivers induced heavy precipitation and flooding in the western U.S. simulated by the WRF regional climate model. Geophys. Res. Lett., 36, L03820, https://doi.org/10.1029/2008GL036445.

Liu, X., X. Ren, and X.-Q. Yang, 2016: Decadal changes of multiscale water vapor transport and atmospheric river associated with the Pacific decadal oscillation and the North Pacific Gyre Oscillation. J. Hydrometeor., 17, 273-285, https://doi.org/10.1175/ JHM-D-14-0195.1.

Lu, D., L. R. Leung, F. Song, and J. Lu, 2018: Roles of SST versus internal atmospheric variability in winter extreme precipitation variability along the U.S. West Coast. J. Climate, 31, 80398058, https://doi.org/10.1175/JCLI-D-18-0062.1.

Malloy, J. W., and Coauthors, 2015: A surface wind extremes ("wind lulls" and "wind blows") climatology for central North America and adjoining oceans (1979-2012). J. Appl. Meteor. Climatol., 54, 643-657, https://doi.org/10.1175/JAMC-D-140009.1.

Meehl, G. A., C. Tebaldi, H. Y. Teng, and T. C. Peterson, 2007: Current and future U.S. weather extremes and El Niño. Geophys. Res. Lett., 34, L20704, https://doi.org/10.1029/ 2007 GL031027.

Mundhenk, B. D., E. A. Barnes, and E. D. Maloney, 2016: Allseason climatology and variability of atmospheric river frequencies over the North Pacific. J. Climate, 29, 4885-4903, https://doi.org/10.1175/JCLI-D-15-0655.1.

Murakami, M., 1979: Large-scale aspects of deep convective activity over the GATE area. Mon. Wea. Rev., 107, 994-1013, https://doi.org/10.1175/1520-0493(1979)107<0994:LSAODC>2. $0 . \mathrm{CO} ; 2$.

Nash, D., D. Waliser, B. Guan, H. Ye, and F. M. Ralph, 2018: The role of atmospheric rivers in extratropical and polar hydroclimate. J. Geophys. Res. Atmos., 123, 6804-6821, https:// doi.org/10.1029/2017JD028130.

Neiman, P. J., F. M. Ralph, G. A. Wick, J. D. Lundquist, and M. D. Dettinger, 2008: Meteorological characteristics and overland precipitation impacts of atmospheric rivers affecting the west coast of North America based on eight years of SSM/I satellite observations. J. Hydrometeor., 9, 22-47, https://doi.org/ 10.1175/2007JHM855.1.

Newell, R. E., N. E. Newell, Y. Zhu, and C. Scott, 1992: Tropospheric rivers?-A pilot study. Geophys. Res. Lett., 19, 2401-2404, https://doi.org/10.1029/92GL02916.

Newman, M., G. N. Kiladis, K. M. Weickmann, F. M. Ralph, and P. D. Sardeshmukh, 2012: Relative contributions of synoptic and low-frequency eddies to time-mean atmospheric moisture transport, including the role of atmospheric rivers. J. Climate, 25, 7341-7361, https://doi.org/10.1175/JCLI-D-11-00665.1.

Oliver, E. C. J., and Coauthors, 2018: Longer and more frequency marine heatwaves over the past century. Nat. Commun., 9, 1324, https://doi.org/10.1038/s41467-018-03732-9.

Payne, A. E., and G. Magnusdottir, 2014: Dynamics of landfalling atmospheric rivers over the North Pacific in 30 years of MERRA reanalysis. J. Climate, 27, 7133-7150, https://doi.org/ 10.1175/JCLI-D-14-00034.1.

—, and - 2015: An evaluation of atmospheric rivers over the North Pacific in CMIP5 and their response to warming under RCP 8.5. J. Geophys. Res. Atmos., 120, 11 173-11 190, https:// doi.org/10.1002/2015JD023586.

Peterson, T. C., X. Zhang, M. Brunet-India, and J. L. Va'zquezAguirre, 2008: Changes in North American extremes derived 
from daily weather data. J. Geophys. Res., 113, D07113, https://doi.org/10.1029/2007JD009453.

Ralph, F. M., P. J. Neiman, G. A. Wick, S. I. Gutman, M. D. Dettinger, D. R. Cayan, and A. B. White, 2006: Flooding on California's Russian River: Role of atmospheric rivers. Geophys. Res. Lett., 33, L13801, https://doi.org/10.1029/ 2006 GL026689.

— , and Coauthors, 2017: Atmospheric rivers emerge as a global science and applications focus. Bull. Amer. Meteor. Soc., 98, 1969-1973, https://doi.org/10.1175/BAMS-D-16-0262.1.

—, J. J. Rutz, J. M. Cordeira, M. Dettinger, M. Anderson, D. Reynolds, L. J. Schick, and C. Smallcomb, 2019: A scale to characterize the strength and impacts of atmospheric rivers. Bull. Amer. Meteor. Soc., 100, 269-289, https://doi.org/ 10.1175/BAMS-D-18-0023.1.

Ren, X., X.-Q. Yang, and H. Hu, 2017: Subseasonal variations of wintertime North Pacific evaporation, cold air surges and water vapor transport. J. Climate, 30, 9475-9491, https:// doi.org/10.1175/JCLI-D-17-0140.1.

Rivera, E. R., F. Dominguez, and C. L. Castro, 2014: Atmospheric rivers and cool season extreme precipitation events in the Verde River basin of Arizona. J. Hydrometeor., 15, 813-829, https://doi.org/10.1175/JHM-D-12-0189.1.

Ropelewski, C. F., and M. S. Halpert, 1986: North American precipitation and temperature patterns associated with the El Niño/Southern Oscillation (ENSO). Mon. Wea. Rev., 114, 2352-2362, https://doi.org/10.1175/1520-0493(1986)114<2352: NAPATP $>2.0 . \mathrm{CO} ; 2$.

—_, and ——, 1987: Global and regional scale precipitation associated with E1 Niño/southern oscillation. Mon. Wea. Rev., 114, 2352-2362, https://doi/org/10.1175/1520-0493(1987) 115<1606:GARSPP>2.0.CO;2.

Rutz, J. J., W. J. Steenburgh, and F. M. Ralph, 2014: Climatological characteristics of atmospheric rivers and their inland penetration over the western United States. Mon. Wea. Rev., 142, 905-921, https://doi.org/10.1175/MWR-D-13-00168.1.

Schneider, T., P. A. O'Gorman, and X. J. Levine, 2010: Water vapor and the dynamics of climate changes. Rev. Geophys., $\mathbf{4 8}$, RG3001, https://doi.org/10.1029/2009RG000302.

Seager, R., and N. Naik, 2012: A mechanisms-based approach to detecting recent anthropogenic hydroclimate change. J. Climate, 25, 236-261, https://doi.org/10.1175/JCLI-D-1100056.1.

,-- , and L. Vogel, 2012: Does global warming cause intensified interannual hydroclimate variability? J. Climate, 25, 3355-3372, https://doi.org/10.1175/JCLI-D-11-00363.1.

Shang, W., S. Li, X. Ren, and K. Duan, 2020: Event-based extreme precipitation in central-eastern China: Large-scale anomalies and teleconnections. Climate Dyn., 54, 2347-2360, https:// doi.org/10.1007/s00382-019-05116-1.

Shields, C. A., and Coauthors, 2018: Atmospheric River Tracking Method Intercomparison Project (ARTMIP): Project goals and experimental design. Geosci. Model Dev., 11, 2455-2474, https://doi.org/10.5194/gmd-11-2455-2018.

Sohn, B. J., E. A. Smith, F. R. Robertson, and S.-C. Park, 2004: Derived over-ocean water vapor transports from satellite-retrieved $E-P$ datasets. J. Climate, 17, 13521365, https://doi.org/10.1175/1520-0442(2004)017<1352:DOWVTF> 2.0.CO;2.

Tan, Y. H., F. Zwiers, S. Yang, C. Li, and K. Q. Deng, 2020: The role of circulation and its changes in present and future atmospheric rivers over western North America. J. Climate, 33, 12611281, https://doi.org/10.1175/JCLI-D-19-0134.1.

Trenberth, K. E., 1997: The definition of El Niño. Bull. Amer. Meteor. Soc., 78, 2771-2777, https://doi.org/10.1175/15200477(1997)078<2771:TDOENO > 2.0.CO;2.

, 1999: Atmospheric moisture recycling: Role of advection and local evaporation. J. Climate, 12, 1368-1381, https://doi.org/ 10.1175/1520-0442(1999)012<1368:AMRROA > 2.0.CO;2.

_ L. Lmith, T. Qian, A. Dai, and J. Fasullo, 2007: Estimates of the global water budget and its annual cycle using observational and model data. J. Hydrometeor., 8, 758-769, https:// doi.org/10.1175/JHM600.1.

Tsuji, H., and Y. N. Takayabu, 2019: Precipitation enhancement via the interplay between atmospheric rivers and cutoff lows. Mon. Wea. Rev., 147, 2451-2466, https://doi.org/10.1175/ MWR-D-18-0358.1.

Vittal, H., S. Karmakar, and S. Ghosh, 2013: Diametric changes in trends and patterns of extreme rainfall over India from pre1950 to post-1950. Geophys. Res. Lett., 40, 3253-3258, https:// doi.org/10.1002/grl.50631.

Waliser, D., and B. Guan, 2017: Extreme winds and precipitation during landfall of atmospheric rivers. Nat. Geosci., 10, 179183, https://doi.org/10.1038/ngeo2894.

Wang, B., R. G. Wu, and X. H. Fu, 2000: Pacific-East Asia teleconnection: How does ENSO affect East Asian climate? J. Climate, 13, 1517-1536, https://doi.org/10.1175/15200442(2000)013<1517:PEATHD > 2.0.CO; 2 .

Wang, L., and W. Chen, 2010: How well do existing indices measure the strength of the East Asian winter monsoon? $A d v$. Atmos. Sci., 27, 855-870, https://doi.org/10.1007/s00376-0099094-3.

Warner, M. D., C. F. Massa, and E. P. Salathé, 2012: Wintertime extreme precipitation events along the Pacific northwest coast: Climatology and synoptic evolution. Mon. Wea. Rev., 140, 2021-2043, https://doi.org/10.1175/MWR-D-11-00197.1.

Wu, X. S., S. L. Guo, J. B. Yin, G. Yang, Y. X. Zhong, and D. D. Liu, 2018: On the event-based extreme precipitation across China: Time distribution patterns, trends, and return levels. J. Hydrol., 562, 305-317, https://doi.org/10.1016/j.jhydrol. 2018.05.028.

Yang, S., Z. Li, J.-Y. Yu, X. Hu, W. Dong, and S. He, 2018: El NiñoSouthern Oscillation and its impact in the changing climate. Natl. Sci. Rev., 5, 840-857, https://doi.org/10.1093/nsr/nwy046.

Yu, J.-Y., and Y. Zou, 2013: The enhanced drying effect of CentralPacific El Niño on US winter. Environ. Res. Lett., 8, 014019, https://doi.org/10.1088/1748-9326/8/1/014019.

Zhou, L.-T., and R. G. Wu, 2010: Respective impacts of the East Asian winter monsoon and ENSO on winter rainfall in China. J. Geophys. Res., 115, D02107, https://doi.org/10.1029/ 2009JD012502.

Zhou, T.-J., B. Wu, and L. Dong, 2014: Advances in research of ENSO changes and the associated impacts on Asian-Pacific climate. Asia-Pac. J. Atmos. Sci., 50, 405-422, https://doi.org/ 10.1007/s13143-014-0043-4.

Zhu, Y., and R. E. Newell, 1998: A proposed algorithm for moisture fluxes from atmospheric rivers. Mon. Wea. Rev., 126, 725-735, https://doi.org/10.1175/1520-0493(1998)126<0725: APAFMF $>2.0 . \mathrm{CO} ; 2$.

Zwiers, F. W., and H. V. Storch, 1995: Taking serial correlation into account in tests of the mean. J. Climate, 8, 336-351, https://doi.org/10.1175/1520-0442(1995)008<0336:TSCIAI > 2.0.CO;2. 